\title{
Cell division protein FtsZ: from structure and mechanism to antibiotic target
}

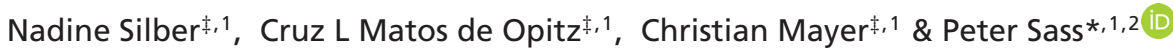 \\ ${ }^{1}$ Department of Microbial Bioactive Compounds, Interfaculty Institute of Microbiology \& Infection Medicine, University of \\ Tübingen, Auf der Morgenstelle 28, Tübingen 72076, Germany \\ ${ }^{2}$ German Center for Infection Research (DZIF), partner site Tübingen, Tübingen 72076, Germany \\ *Author for correspondence: peter.sass@uni-tuebingen.de \\ $\ddagger^{\ddagger}$ Authors contributed equally
}

\begin{abstract}
Antimicrobial resistance to virtually all clinically applied antibiotic classes severely limits the available options to treat bacterial infections. Hence, there is an urgent need to develop and evaluate new antibiotics and targets with resistance-breaking properties. Bacterial cell division has emerged as a new antibiotic target pathway to counteract multidrug-resistant pathogens. New approaches in antibiotic discovery and bacterial cell biology helped to identify compounds that either directly interact with the major cell division protein FtsZ, thereby perturbing the function and dynamics of the cell division machinery, or affect the structural integrity of FtsZ by inducing its degradation. The impressive antimicrobial activities and resistance-breaking properties of certain compounds validate the inhibition of bacterial cell division as a promising strategy for antibiotic intervention.
\end{abstract}

First draft submitted: 30 December 2019; Accepted for publication: 22 April 2020; Published online: 21 July 2020

Keywords: ADEP • antimicrobials • cytokinesis • divisome • drug discovery • MRSA • PC $190723 \bullet$ VRE

Cell division is a central and vital process for almost all living organisms. In bacteria, the generation of progeny commonly relies on binary fission of a parent cell into identical daughter cells. To assure the correct execution of cell division, and thus viability of the offspring, parent cells have to coordinate a plethora of cellular processes in time and space, such as overall biomass increase, chromosome duplication, membrane syntheses, production of cell wall with septum formation as well as timely segregation of daughter cells to complete cytokinesis. In principle, bacterial cell division is orchestrated by a macromolecular complex of proteins, the so-called divisome, which mediates the individual and distinct steps during cell division. Here, FtsZ acts as a pacemaker of divisome formation and cytokinesis, as it assembles into protofilaments to form a ring-like structure, the FtsZ-ring (or Z-ring), at the prospective division site where it functions as a scaffold for further members of the divisome. As the cell cycle proceeds, the divisome constricts and synthesizes septal peptidoglycan to allow for septum formation and eventually cytokinesis.

Considering the global spread of multidrug-resistant bacteria, which pose an increasing threat to the public healthcare system and the community, intensified research on new antibacterial targets is urgently needed. In recent years, bacterial cell division has been recognized as a promising new target pathway for antibiotic attack, and new antibiotics have been described, which interfere with this central process by different means. We here review the structural and biochemical features of the central division protein Fts $Z$ as well as its role in the course of division, and we address current approaches to deregulate FtsZ by antibiotic action.

\section{Crystal structure \& abundance of FtsZ}

Filamenting temperature sensitive mutant Z (FtsZ) was first described for Escherichia coli in 1980 [1], based on the finding that various isolated mutants of $E$. coli were not able to divide but grew into long filaments at a nonpermissive temperature of $42^{\circ} \mathrm{C}$ [2]. A decade later in a breakthrough study, Bi and Lutkenhaus could show that FtsZ self-assembles into a ring-like structure at the future site of division [3], which depended on the binding and

Future $\because$ Medicine 
subsequent hydrolysis of the nucleotide guanosine-5'-triphosphate (GTP) [3-6]. The likely presence of cytoskeletal elements in bacterial cells, probably functionally analogous to the roles of actin or tubulin during cytokinesis in eukaryotic cells, challenged the view regarding bacteria at that time and supported the emerging awareness that bacteria are more than just a bag full of enzymes, thereby triggering a multitude of further investigations on FtsZ.

In 1998, Löwe and Amos reported the first crystal structure of FtsZ, which was refined later at a resolution of $1.7 \AA$ (PDB: 1FSZ and 2VAP, respectively; protein data bank, https://www.rcsb.org) [7-9]. Resolving amino acid residues 23-356 of FtsZ from the hyper-thermophilic methanogen Methanocaldococcus jannaschii (MjFtsZ, formerly Methanococcus jannaschii; total protein length: 364 amino acids), the first crystal structure revealed two major protein domains, in particular an N-terminal GTP-binding domain and a C-terminal domain, and it proved structural homology to the eukaryotic cytoskeletal protein tubulin (Figure 1A \& B). In both $\beta$-tubulin and FtsZ, the $\mathrm{N}$-terminal domain is composed of six $\beta$-sheets arranged in parallel and surrounded by $\alpha$-helices H1-H6. The Cterminal domain consists of four parallel arranged $\beta$-sheets (S7-S10), which are surrounded by $\alpha$-helices H8-H10, and it is connected with the $\mathrm{N}$-terminal domain via the central $\alpha$-helix H7. MjFtsZ carries an additional $\alpha$-helix $\mathrm{H} 0$ at the N-terminus, which is absent in tubulin and FtsZ from other described organisms. Moreover, tubulin carries two additional long $\alpha$-helices at the C-terminus $(\mathrm{H} 11+\mathrm{H} 12)$, while MjFtsZ is characterized by a small $\beta$-hairpin region $(\mathrm{S} 11+\mathrm{S} 12)$ at this position $[7,10]$. Noteworthy, MjFtsZ additionally features an elongated, more than 30 amino acids long $\mathrm{N}$-terminal tail that protrudes the globular core protein [7], which is significantly shorter in other bacteria including E. coli, Pseudomonas aeruginosa, Bacillus subtilis, Streptococcus pneumoniae, Staphylococcus aureus and Mycobacterium tuberculosis.

Although the topology of the GTP-binding domains of FtsZ and tubulin are analogous to the ones found in classical GTPases such as EF-Tu (elongation factor thermo unstable; PDB: 1TUI) [15,16], the structural data showed that the mechanism of nucleotide binding is different [10]. Fts Z and tubulin involve seven segments for nucleotide binding, whereas only five segments are involved in classical GTPases. In tubulin and FtsZ, phosphate binding is sustained by loops T1-T4, of which loop T4 carries the highly conserved glycine-rich tubulin signature motif with the sequence pattern GGGTG[S/T]G, while loop T5 is involved in ribose binding and loop T6 as well as helix $\mathrm{H} 7$ are in contact with the guanine base. In fact, nucleotide binding by FtsZ and tubulin is more similar to the protein GAPDH, even though GAPDH binds a different nucleotide, namely $\mathrm{NAD}^{+}$. These observations led to the categorization of FtsZ and tubulin as a distinct family of GTP-hydrolyzing enzymes [10], thus further supporting a homologous relationship between bacterial FtsZ and eukaryotic tubulin.

With the genomic era, it emerged that FtsZ is indeed largely conserved across the domains Bacteria and Archaea [17] with only a few exceptions including the phyla Crenarchaeota, Planctomycetes, Chlamydiae [18-20], or the strains Carsonella ruddii [21], Ureaplasma urealyticum [22] and Mycoplasma mobile [23]. Moreover, homologous proteins of FtsZ also mediate the division of plastids in algae and plants [24,25]. Accordingly, the tubulin signature motif is conserved in various sequences from bacteria, archaea, eukarya and even bacteriophages as listed in the PROSITE database (PS00227, PDOC00199; https://prosite.expasy.org). Interestingly, even though FtsZ and tubulin share a high structural similarity, their conserved $\mathrm{N}$-terminal domains reveal an amino acid sequence identity of only $10 \%$. Here, conserved residues are mostly located in regions that are involved in nucleotide binding such as the T4 loop [10]. On the contrary, primary structure analyses of FtsZ from S. aureus, B. subtilis, M. tuberculosis, S. pneumoniae and $E$. coli revealed at least $42 \%$ amino acid sequence identity with the highest identity of $68 \%$ observed between FtsZ from B. subtilis (BsFtsZ) and S. aureus (SaFtsZ). Nonetheless, due to its structural and functional homology with eukaryotic tubulin, and together with the ubiquitous abundance in bacteria and even eukaryotic plastids, FtsZ is consequently assumed to be the ancestral progenitor of eukaryotic tubulin [26]. In an evolutionary context, it is further noteworthy that the $\mathrm{N}$ - and C-terminal domains of FtsZ fold independently, in other words, they can be expressed separately and still show GTPase activity when joined (as shown for Thermotoga maritima FtsZ) [11], suggesting that both domains may have evolved from two independent proteins.

\section{Functional regions of the FtsZ protein}

In principle, FtsZ may be subdivided into the following five distinct functional regions: a poorly conserved $\mathrm{N}$-terminal peptide (NTP); a globular, highly conserved core region including the major parts of the N-and Cterminal domains as well as the GTP-binding pocket; an unstructured C-terminal linker (CTL); a short, conserved C-terminal tail (CTT); and a C-terminal variable region (CTV) (Figure 1B) [17,27].

The NTP region is poorly conserved and can have a length of a few to more than 60 amino acids. The NTP region ends with the conserved isoleucine at the beginning of the 'Rossmann fold' [28], the defined start of the Fts $Z$ 


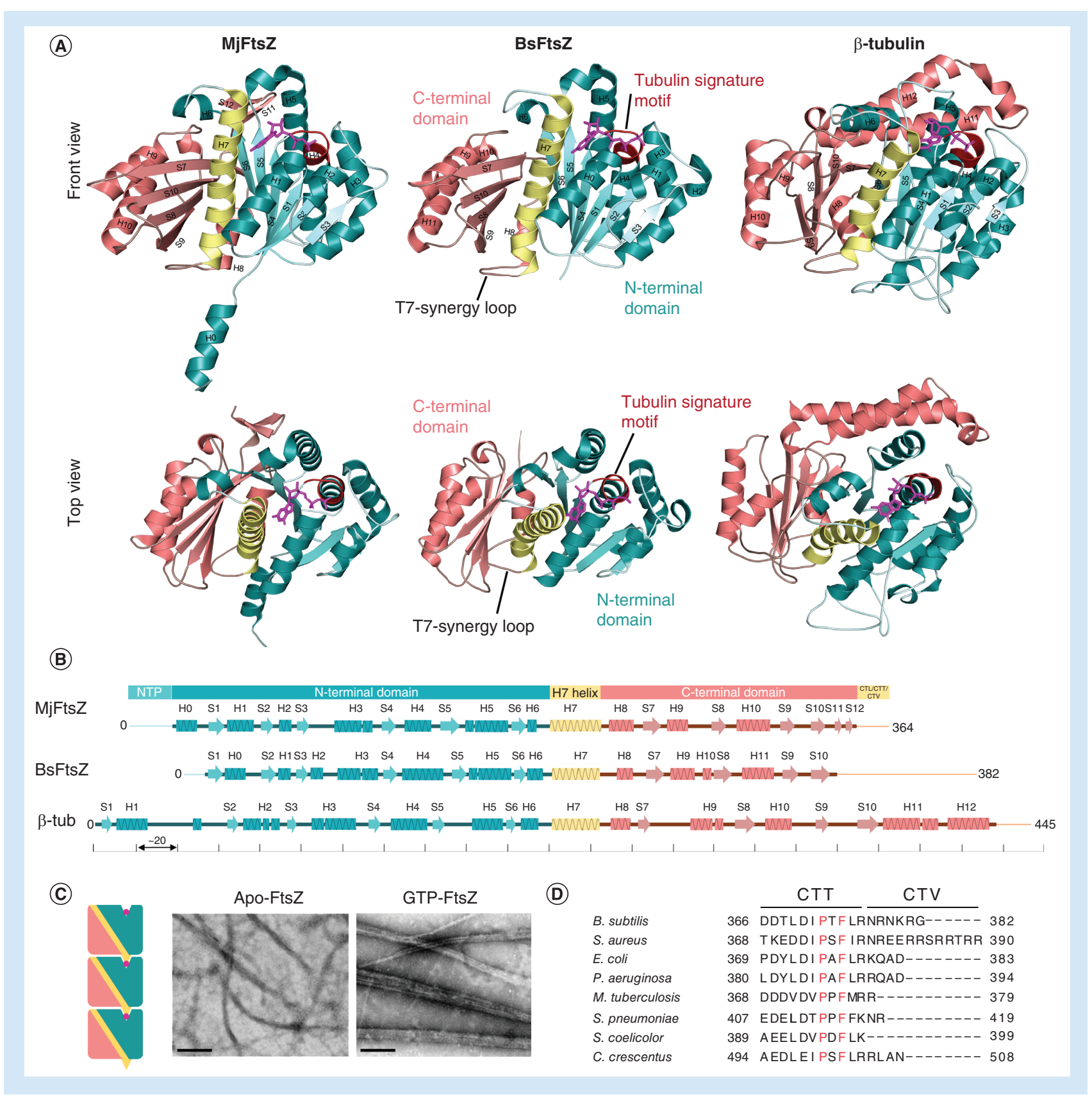

Figure 1. Crystal structure and functional regions of FtsZ. (A) Crystal structure of FtsZ from Methanocaldococcus jannaschii and Bacillus subtilis as well as of tubulin. The crystal structures of GDP-bound M. jannaschii FtsZ (MjFtsZ; residues 20-354, PDB: 2VAP, [11]), GTP $\gamma$ S-bound B. subtilis FtsZ (BsFtsZ; residues 12-316, PDB: 2RHO, [12]) and GDP-bound $\beta$-tubulin (residues 2-437, PDB: 1JFF, [13]) are depicted as front and top view as indicated. The $\mathrm{N}$-terminal domain including the GTP-binding site is colored in cyan and the C-terminal domain in salmon with the connecting $\alpha$-helix H7 in yellow. The conserved tubulin signature motif GGGTG[S/T]G is marked in red. Bound nucleotides are colored in magenta. $\alpha$-helices $(\mathrm{H})$ and $\beta$-sheets $(\mathrm{S})$ are numbered in the crystal structures. (B) Functional regions of MjFtsZ and secondary structure of MjFtsZ, BsFtsZ and $\beta$-tubulin. FtsZ comprises five distinct functional regions: i) a short, unstructured and poorly conserved N-terminal peptide (NTP); ii) a globular, highly conserved core region including major parts of the N-and C-terminal domains with the GTP-binding pocket and the connecting $\alpha$-helix H7; iii) an unstructured C-terminal linker (CTL); iv) a short, conserved C-terminal tail (CTT); as well as v) a C-terminal variable region (CTV). $\alpha$-helices $(\mathrm{H})$ and $\beta$-sheets $(\mathrm{S})$ are numbered and illustrated as boxes and arrows, respectively. The unsolved NTP region is marked in light blue, the unsolved CTL and CTT/CTV regions are depicted as a salmon-colored line. (C) Head-to-tail polymerization of FtsZ and protofilament formation. Left image: Schematic of the head-to-tail association of individual FtsZ monomers that polymerize into protofilaments. Here, the active site of the GTPase is formed at the interface of two adjacent FtsZ subunits by the T7 synergy loop of the 'upper' and the GTP-bound nucleotide-binding pocket of the 'lower' FtsZ monomer. The N-terminal domain is depicted in cyan, the C-terminal domain in salmon and the connecting $\alpha$-helix $\mathrm{H} 7$ with the T7 synergy loop in yellow (the latter indicated as bottom face triangle). GTP is indicated as a pink dot. Right image: Electron micrographs of polymers formed by apo-FtsZ or GTP-bound FtsZ. Scale bars indicate $200 \mathrm{~nm}$. (D) Amino acid sequence alignment of the CTT and CTV regions of FtsZ from different organisms. Highly conserved residues are marked in red.

Electron micrographs were reproduced with permission from [14] and reprinted with permission from Wiley. 
core domain [17]. Accordingly, the NTP regions of BsFtsZ (PDB: 2RHO) and MjFtsZ (PDB: 2VAP) comprise 13 and 39 amino acids $[7,8,12]$, respectively, while in the phylum of cyanobacteria the NTP reaches a length of up to 68 amino acids [17]. In most bacteria including Firmicutes and Proteobacteria, the NTP has not yet been assigned a decided function; however, in cyanobacteria, it is highly conserved and recent data demonstrated its importance for Z-ring formation in these bacteria. Here, efforts were directed to delete the amino acids 2-51 of FtsZ in Anabaena sp. PCC 7120, which repeatedly failed, suggesting a more important role for the extended NTP in cyanobacteria [29]. Subsequent co-expression of N-terminally truncated FtsZ together with wild-type FtsZ led to an increased cell size of Anabaena accompanied by hampered cell division. Results obtained from bacterial two-hybrid assays revealed an interaction of the NTP of FtsZ with the cell division protein SepF [29], which has been previously shown to be an essential, FtsZ-interacting septal protein in Synechocystis PCC 6803 [30].

The globular, highly conserved core region of FtsZ comprises the main parts of the $\mathrm{N}$-terminal domain with the GTP-binding site as well as the C-terminal domain. To build the Z-ring, the core region provides the interface for a head-to-tail polymerization of individual FtsZ monomers into protofilaments (Figure 1C), thereby triggering GTPase activity. During polymerization, the active site of the GTPase is formed at the interface of two adjacent subunits of FtsZ. Here, the 'upper' subunit inserts its C-terminal T7 synergy loop into the GTP-bound nucleotide-binding pocket of the 'lower' subunit, thereby inducing GTP hydrolysis [4,10,31]. Crystal structures of nucleotide-bound M. tuberculosis FtsZ (MtbFtsZ), harboring either guanosine-5'-diphosphate (GDP) or the nonhydrolyzable GTP analog guanosine-5'-O-3-thiotriphosphate (GTP $\gamma S)$, suggested a switch mechanism of the FtsZ core during GTP hydrolysis (PDB: 1RQ7, 1RLU) [32]. Here, the GTP $\gamma$-phosphate appears to stabilize the T3 loop in a compact tension state (T-state), while in a GDP-bound crystal in the absence of the $\gamma$-phosphate, the T3 loop is in a relaxed conformation (R-state) [33,34]. It was therefore assumed that hydrolysis of the nucleotide may trigger a switch from the T-state to the R-state of the T3 loop, thus weakening the longitudinal interaction between loops $\mathrm{T} 3$ and $\mathrm{T} 7$ of two adjacent FtsZ subunits. Such a switch could lead to a hinge-opening around the pivot point and bending of the filament, thereby generating mechanical work, which causes an inward force on the membrane that is needed for Z-ring constriction during cytokinesis [33,34]. Similarly, a structural switch of the T3 loop from the T- to the R-state may also be caused by interactions of GTP with the T7 loop of the next subunit [35]. On the contrary, different MjFtsZ structures showed only negligible differences in the T3 loop region when bound to either GDP or GTP compared with apo-MjFtsZ (PDB: 1W58, 1W5B, 1W59, 1FSZ) [7,11]. Nucleotide-dependent conformational changes were also not observed for Aquifex aeolicus FtsZ (AaFtsZ) comparing crystal structures of AaFtsZ:GDP and AaFtsZ:8-morpholino-GTP $[9,36$. Further, the crystal structure of SaFtsZ bound to either GTP or GDP did not show a conformational switch of the T3 loop, but revealed an opened and a closed conformation of the FtsZ core [37]. When compared with the closed conformation of SaFtsZ (PDB: 5MN8), the open conformation showed a rotation between the $\mathrm{N}$ - and $\mathrm{C}$-terminal domains, thereby opening a cleft between the two domains while shifting the central $\alpha$-helix H7 downward (PDB: 5MN4). The opened conformation seems to be established upon FtsZ polymerization, whereas the closed conformation is adopted in the monomeric state of FtsZ, suggesting that the conformational switch of FtsZ depends on polymerization rather than nucleotide binding alone. Here, categorizing previous Fts $Z$ crystal structures from different organisms revealed a higher similarity of most Fts $Z$ structures to the closed conformation of SaFtsZ [37].

Regarding the interaction between the core regions of different FtsZ subunits, crystal structures of polymeric MtbFtsZ bound to GDP revealed a series of hydrogen bonds as well as hydrophobic interactions at the interface of two FtsZ monomers that are intimately involved in assembly. To confirm the importance of the observed intersubunit contacts, the identified hydrophobic amino acids with acidic residues were mutated in $E$. coli FtsZ (EcFtsZ; i.e., F137E, G139E, L178E, A181E, L205E, L272E, V292E, M206E and I294E). Here, the mutations abrogated GTPase activity in vitro, and in vivo complementation approaches with these mutants failed [34]. Furthermore, lateral interactions between FtsZ protofilaments are promoted by the widely conserved residues $\mathrm{Glu}_{83}$ and $\operatorname{Arg}_{85}$ that are both located within $\alpha$-helix H3. In E. coli, mutations at these two positions led to decreased viability, and mutant proteins were impaired in polymerization and GTPase activity in vitro, suggesting a major role of these residues in longitudinal and lateral interactions [38]. It is further suggested that lateral contacts are mostly ascribed to van der Waals interactions, which are weaker compared with hydrophobic interactions at the longitudinal interface, and it seems that such lateral interactions between FtsZ protofilaments play an important role for correct cytokinesis, as substitutions at the lateral site of FtsZ strongly affect cell division [39].

Only a few modulatory proteins have yet been reported to interact with the core region of FtsZ, such as the SOS cell division inhibitor SulA [40], which is induced upon DNA damage and binds to the T7 loop surface of FtsZ. 
A crystal structure of FtsZ bound to SulA from P. aeruginosa showed that SulA entirely covers the T7 loop, and by doing so prevents polymerization of FtsZ (PDB: 1OFU) [41]. MinC is a further inhibitor of cell division that interacts with residues in the C-terminal core region of BsFtsZ. More precisely, interaction with the core region occurs via amino acids within as well as in close proximity to $\alpha$-helices H9 and H10 (i.e., T232I, K243R, I245F, D255V, V260A, A285T, D287V, I293T and V310A) [42]. The region around H9 and H10 is characterized by a negatively charged surface that was suggested to be important for the binding of MinC [42], which matches the finding that the MinC-FtsZ interaction is $\mathrm{pH}$ dependent [43]. In E. coli, the same regions of FtsZ (H10 and the CTT) are involved in MinC binding, but the residues differ from those observed for BsFtsZ [44,45].

The unstructured CTL (or spacer) spans the region between the globular core of Fts $Z$ and the extreme CTT/CTV region, and it is highly variable regarding its length and amino acid sequence. Depending on the organism, the CTL comprises up to 330 residues [17] and it is predicted to be mostly disordered, thus explaining why this region is commonly not resolved in crystal structures. Deletion of the CTL region results in impaired protofilament formation in vitro, indicating an important role in establishing lateral interactions between protofilaments. Also, deletion of CTL leads to a decreased GTPase activity with a concomitant increase of the critical concentration of FtsZ required for filamentation, revealing a decline in cooperative assembly [46]. In B. subtilis, CTL deletion mutants are also incapable of developing an intact Z-ring and show a delocalization of FtsZ, leading to a filamentous cell shape. Intriguingly, deletion of only $50 \%$ of the CTL region, scrambling of the CTL sequence or exchanging the entire CTL region by an unrelated, intrinsically disordered peptide sequence restores normal cell division. However, extending the CTL region significantly beyond the normal number of residues (here: $>249$ in B. subtilis) or replacing it with helical repeats (i.e., residues 398-455 from human beta-catenin) results in filamentous cells that are unable to divide [46]. While the amino acid sequence and length (to a certain extent) appears less critical, the CTL region obviously functions as a flexible tether that provides a defined distance from the membrane, where FtsZ is anchored via modulatory proteins that interact with the conserved CTT region of FtsZ [46,47]. In addition, cryo-electron microscopy (cryo-EM) and small-angle $\mathrm{x}$-ray scattering (SAXS) experiments showed that the distance between individual FtsZ protofilaments is reduced from $70 \AA$ to approximately $55 \AA$ when the CTL region is deleted, indicating a role of the CTL region for the correct spacing between protofilaments in higher-ordered Fts $Z$ bundles, thereby providing a certain flexibility that is needed for Fts $Z$ dynamics [48]. Hence, the CTL region is important for protofilament formation and correct assembly of the Z-ring.

The extreme CTT region comprises approximately 11 amino acid residues (Figure 1D), which together with the CTV region is designated the 'grappling hook peptide' (GHP) that acts as a central hub for FtsZ-interacting proteins [46]. During the last decades, several modulatory proteins related to the division machinery have been identified to interact with the CTT region, including negative regulators of Z-ring assembly, such as EzrA [49,50], MinC [42,51,52] or SlmA [53-55], as well as positive regulators, including FtsA [56-58], ZipA [56,59-62], SepF [63], or ZapC and ZapD [64,65]. A more detailed description of these regulatory proteins and their roles in the course of cell division is addressed in a later section of this review.

The CTV region is highly variable and comprises only a few amino acid residues (Figure 1D). The CTV region of BsFtsZ (NRNKRG) is highly positively charged and is important for lateral interactions between FtsZ protofilaments. In contrast, the CTV region of EcFtsZ (KQAD) is neutrally charged. Intriguingly, EcFtsZ primarily forms single-stranded filaments in vitro with a length of approximately $200 \mathrm{~nm}$, whereas BsFtsZ assembles into stable, large protofilament bundles that are composed of rings and sheets of single-stranded filaments (approximately $130 \mathrm{~nm}$ in length) under the same conditions [27]. Truncation of the CTT-CTV region in BsFtsZ leads to defects in lateral interactions, while the same truncations do not affect the polymerization behavior of EcFtsZ with protofilaments that are only slightly shorter in length. Chimeric proteins were generated by swapping the CTV regions of BsFtsZ and EcFtsZ. Here, chimeric EcFtsZ now assembles into thick filaments, whereas chimeric BsFtsZ only polymerizes into straight protofilaments, indicating that the CTV region of FtsZ is crucial for lateral interactions in vitro. In vivo, the importance of the CTV region was further emphasized by the inability of the chimeric proteins to support normal cell division in the respective bacterial species [27].

\section{Z-ring assembly \& force generation}

In most bacteria, FtsZ is regarded as the central player and pace-making protein of cell division. To build the Z-ring, the scaffold that further proteins of the cytokinetic apparatus adhere to, FtsZ self-polymerizes in a GTPdependent manner to form protofilaments and larger bundles thereof, eventually assembling into a discontinuous ring-like structure at the inner side of the cytoplasmic membrane [3,66,67], marking the prospective site of division. 
Here, the protein concentration of FtsZ plays a critical role during protofilament and Z-ring assembly. In vitro, nucleotide-dependent polymerization of EcFtsZ occurs only above a critical concentration (1-2 $\mu \mathrm{M}$ depending on the buffer conditions) [68,69], which results in different types of protofilament structures. Addition of GTP leads to single-stranded straight protofilaments (Figure 1C) that in the presence of the crowding agent DEAEdextran assemble into sheets of straight filaments. Contrariwise, GDP induces the formation of shorter and curved filaments as well as minirings with a diameter of approximately $23 \mathrm{~nm}$ that form tubes in DEAE-dextran [70]. Further, increasing the concentration of EcFtsZ above the critical concentration leads to a higher proportion of double-stranded filaments in vitro $(\sim 9 \mathrm{~nm}$ wide), in contrast to mainly single-stranded filaments ( $\sim 4 \mathrm{~nm}$ wide) observed close to the critical concentration [68]. Accordingly, overexpression of FtsZ in whole cells perturbs Z-ring assembly and results in minicell formation [71].

Once assembling, the Z-ring continues to be a highly dynamic structure that is treadmilling around the division plane, constantly exchanging FtsZ subunits with the cytoplasmic pool (with a half-time of $\sim 10-30$ s), the latter comprising approximately $70 \%$ of the overall cellular pool of FtsZ [72-75]. In vitro experiments with Cy5- and Alexa Fluor 488-labeled FtsZ showed that filaments grow at one end while depolymerization takes place at the opposite end [76]. A study investigating top- $\left(\right.$ Fts $\left.Z_{\mathrm{L} 178 \mathrm{E}}\right)$ and bottom- $\left(F t s Z_{\mathrm{L} 272 \mathrm{E}}\right)$ face mutant proteins of FtsZ showed that FtsZ filaments, in contrast to microtubules, are characterized by bottom-end growth $[34,77]$. Furthermore, the bottom face mutant Fts $\mathrm{L}_{\mathrm{L} 272 \mathrm{E}}$ inhibits cell division in vivo corroborating polymerization at the bottom end [77]. In $B$. subtilis, the rate of FtsZ treadmilling was reported to control both the rate of cell division and peptidoglycan synthesis [73]. In contrast, a recent study by Monteiro and colleagues proposed an alternative model for $S$. aureus that involves two sequential steps as the driving force for septum constriction: a first slow step that is dependent on FtsZ treadmilling, and a second faster step that is driven by peptidoglycan synthesis [78]. Similarly, in S. pneumoniae, the movement of peptidoglycan synthesis enzymes was demonstrated to be independent of FtsZ treadmilling, suggesting that septal FtsZ rings organize the peptidoglycan synthesis complex of the divisome dependent on peptidoglycan substrate availability [79].

In the course of cytokinesis, the divisome constricts to finalize septum formation and cell division. The presence of a membrane-tethered ring-like structure, which is formed by dynamic protofilaments of GTP-consuming FtsZ, promoted the idea that the Z-ring may generate a mechanical force on the bacterial membrane sufficient to allow for the constriction of the division apparatus. In this context, a mathematical model suggested that the minimal force needed for constriction, which the Z-ring has to create in an E. coli cell, would be about $8 \mathrm{pN}$ [80]. By attempting in vitro reconstitution of the Z-ring in liposomes, an FtsZ mutant protein carrying an amphipathic helix for membrane anchoring (instead of the FtsA/ZipA-binding site) assembled into ring-like structures and indeed led to a constriction of the liposome in presence of GTP [81]. An alternative hypothesis argues that inward growth may provide the driving force for constriction, while the role of FtsZ might be that of simply serving as a scaffold [82]. However, in silico simulations indicated that cell wall growth alone is not sufficient for cell division to occur without an initial constriction force provided by the Z-ring [83,84].

\section{Positioning of the Z-ring \& division site selection}

The correct placement of the future division site is crucial and needs to be coordinated with other cellular processes, such as chromosome segregation. In B. subtilis and E. coli, division site selection occurs in a stunningly precise fashion with approximately $2 \%$ deviation off-center midcell [85,86]. To achieve such precision, Z-ring positioning is controlled by distinct regulatory mechanisms. In B. subtilis, spatial regulation is primarily achieved by two negatively-acting regulatory systems, the nucleoid occlusion (NO) and the minicell (Min) systems (Figure 2A). The NO system, driven by the ParB-family protein Noc, prevents premature division events over unsegregated nucleoids [87-89]. To this end, Noc binds to about 70 distinct Noc-binding sites on the chromosome to form nucleoprotein complexes that associate with the cell membrane via an $\mathrm{N}$-terminal amphipathic $\alpha$-helix of the Noc protein [90]. Since the Noc-binding sites are distributed only in the origin-proximal $2 / 3$ of the chromosome and are absent in the terminus region [91], these membrane-bound nucleoprotein complexes are assumed to physically prevent the assembly of the divisome over insufficiently segregated nucleoids [90]. In E. coli, NO is conferred by the SlmA protein [53], which alike Noc in B. subtilis recognizes specific SlmA-binding sites that are distributed all over the chromosome except for the terminus region [92,93]. However, in contrast to Noc in B. subtilis, which does not seem to act directly on FtsZ [91], SlmA has been reported to antagonize Z-ring assembly by directly binding to the CTT region of FtsZ [54,92,94,95]. Thus, although SImA and Noc do not share considerable amino acid sequence identity or structural homology, they fulfill the same function in the bacterial cell yet by different mechanisms [53,89]. 
(A)

\section{(i)}

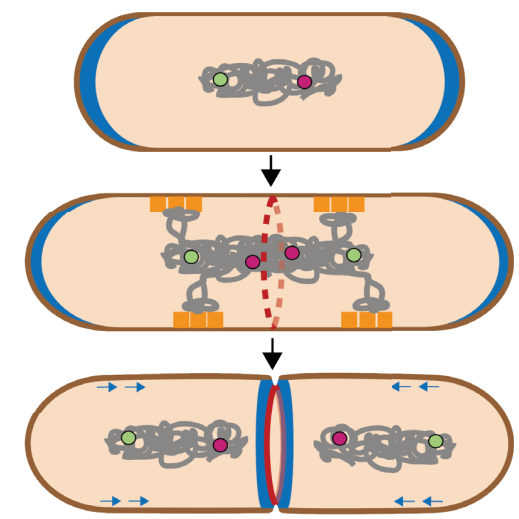

B. subtilis
(B)

(i)

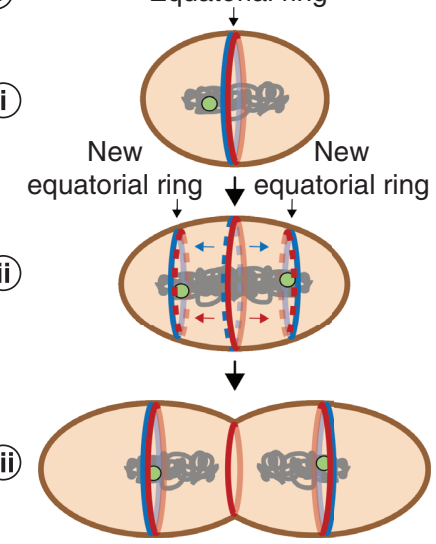

S. pneumoniae

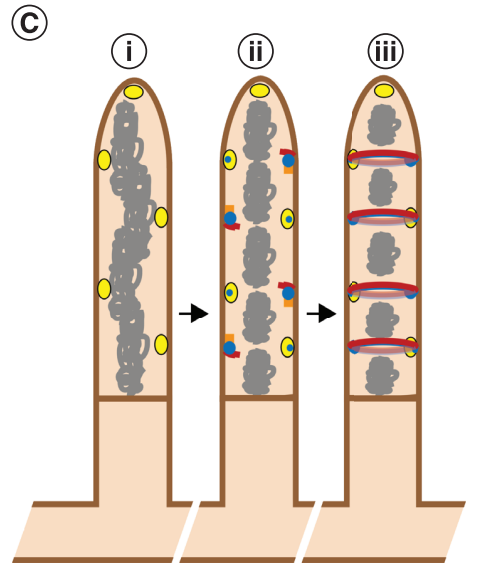

Streptomyces spec.

Figure 2. Division site selection in bacteria. (A) Negative regulation of division site selection in Bacillus subtilis. (i) DivlVA localizes to the cell poles and recruits MinCDJ to form the DivIVA-MinCDJ regulatory complex (in blue), inhibiting Z-ring formation at the old cell poles. (ii) The nucleoid occlusion factor Noc (orange rectangles) binds to the membrane as well as to specific Noc-binding sites on the nucleoid, thereby forming large membrane-associated nucleoprotein complexes that prevent the formation of the Z-ring over the chromosome (indicated by red dotted ring). The origin region of the nucleoid is depicted in green, the terminus-region in pink. (iii) After nucleoids have segregated, a Noc- and Min-free zone is established at mid-cell that allows for Z-ring and subsequent divisome formation (indicated by the continuous red ring). Later, the DivIVA-MinCDJ complex is recruited from the old poles to the current division site, thus preventing the assembly of additional Z-rings close to the new septum (blue arrows indicate the dynamic movement of DivIVA-MinCDJ from the old cell poles to the new/current division site). (B) Positive regulation of division site selection in Streptococcus pneumoniae. (i) In cells undergoing early division, MapZ-rings (in blue) and FtsZ-rings (in red) are localized at the equatorial ring, the current division site. (ii) After initiation of peripheral peptidoglycan synthesis, MapZ bifurcates into two rings that migrate to the future division sites (movement indicated by blue arrows), following the origin of replication (in green). Subsequently, FtsZ, EzrA and FtsA continuously move out from mature septal rings at mid-cell toward the new equatorial MapZ-rings in the prospective daughter cells (depicted as red dashed rings). (iii) Later, MapZ proteins have moved to the new equatorial rings, while the FtsZ-ring and further divisome members remain at the constricting old septum, finalizing cell division. (C) Division site selection in sporogenic cells of streptomycetes. (i) SsgA (yellow circles) localizes in distinct foci along young sporogenic aerial hyphae. At this stage, SsgB is still localized more or less diffusively while FtsZ assembles into spiral-like filaments throughout the sporogenic cell prior to division (not depicted). (ii) SsgA then recruits SsgB (blue circles) to the sporulation-specific cell division site and both proteins co-localize temporarily at the early division stage. In addition, correct localization of SsgB is supported by the membrane protein SepG (orange rectangles). SsgB, in turn, is involved in recruiting FtsZ to the division site and supports FtsZ polymerization. (iii) Regularly spaced Z-rings are then formed at the decided division sites that direct synchronous sporulation septation. While SsgAB and FtsZ remain at the division site, SepG dissociates and re-localizes to the spore periphery (not depicted).

The Min system of B. subtilis, which is characterized by the proteins DivIVA, MinD, MinJ and MinC, prevents the formation of new Z-rings in the regions near the cell poles. Here, DivIVA recognizes the negative curvature of the cell membrane that is generated upon constriction of the divisome in the course of septum formation, thus marking the former division site/the new cell pole [96]. Via the adaptor protein MinJ, DivIVA then directs the membrane-associated Walker-type ATPase MinD to the cell pole [97,98], which again recruits MinC, the actual negative regulator of FtsZ. To inhibit Z-ring formation, MinC directly interacts with the bottom face of the $\alpha$-helix $\mathrm{H} 10$ as well as the CTT region of FtsZ [42], thereby preventing lateral interactions between individual protofilaments of FtsZ, leading to the formation of shorter and curved filaments [43,51,52]. In E. coli, the Min system consists of the proteins MinC, MinD and MinE [99], of which MinC directly interacts with FtsZ, similar to previous observations in B. subtilis [44]. However, unlike in B. subtilis, the Min system of E. coli has an oscillating nature. Here, MinD forms a membrane-bound complex with MinC that is spatially controlled by MinE. MinE oscillates with MinD from one pole of the cell to the other, providing a time-averaged gradient concentration of MinC with higher concentrations at the cell poles and lower concentrations at midcell, thus permitting Fts $Z$ polymerization and Z-ring formation only at midcell [100-105]. Hence, homologous Min proteins fulfill the same function, but yet again, by different mechanisms, thus illustrating the different ways evolution has used to fine-tune the NO and 
Min systems in B. subtilis and E. coli, thereby underlining their importance for division site selection. However, it is noteworthy that individual Min and Noc/SlmA proteins are not essential in B. subtilis or E. coli $[53,89]$, and independent studies in both species revealed that Z-rings may still be positioned at midcell even in the absence of both Min and NO, suggesting additional, yet unknown factors to be involved in division site selection in these species $[106,107]$.

In this context, for example, Caulobacter crescentus lacks both Min and NO systems, but employs a further negatively regulating mechanism mediated by the ParA-like ATPase MipZ. MipZ interacts with the chromosomepartitioning protein ParB to form a bipolar gradient in the predivisional cell, leading to higher concentrations of MipZ at the cell tips. Then, ParB promotes dimerization of MipZ, which in turn prevents polymerization of FtsZ and thus Z-ring formation at the cell poles $[108,109]$. Noteworthy, ParA-like proteins can also act as positive regulators for division site selection, such as PomZ in Myxococcus xanthus, an organism that is also devoid of other known factors for the positioning of the Z-ring. Here, PomZ localizes to the future division site prior to and independent of FtsZ, and then recruits FtsZ [110]. Similarly, correct Z-ring placement in S. pneumoniae depends on positive regulation by the chromosomal origin of replication [111] as well as the MapZ (or LocZ) protein [112,113], the latter localizes to the future division site prior to the arrival of FtsZ (Figure 2B). Here, MapZ is important for establishing the correct division plane, while the oriC region is crucial for the assembly and positioning of the cytokinetic machinery [111]. Another example of positive regulation of Z-ring positioning in the absence of Min and NO systems can be observed in the actinomycete Streptomyces coelicolor, where the SsgAB proteins mark the position for Z-ring assembly and recruit FtsZ to the division site (Figure 2C) [114]. S. aureus lacks a complete Min system but encodes for DivIVA and Noc [115,116]. Here, Noc has a conserved function in spatially regulating Z-ring formation by inhibiting divisome assembly over the nucleoid, consistent with the role of Noc in other bacteria, but interestingly, it is also involved in controlling the initiation of DNA replication in S. aureus [117]. In this context, there is also strong evidence for a role of DNA replication in division site selection in B. subtilis [118-120] and E. coli $[106,121-123]$. Thus, the multiplicity and the joint functions of such inventive regulatory mechanisms, which lead to a tight control of Z-ring positioning, emphasize the central importance of division site selection.

\section{Modulation of the Z-ring by divisome proteins}

The Z-ring is assembled by individual protofilaments of Fts $Z$ and, in principle, appears to be sufficient to generate the constrictive force required for cytokinesis $[81,83,84]$. However, for correct cell division, a plethora of further divisome proteins have to be recruited to the Z-ring, which interact with FtsZ, tethering the Z-ring to the membrane and modulating its dynamics (Figure 3). In total, more than 35 proteins have been identified to be involved in cell division so far [124]. As shown for the two model organisms B. subtilis and E. coli, divisome assembly may be separated into two temporally distinct steps. First, the Z-ring is formed on the inner side of the cytoplasmic membrane by the aid of early-stage cell division proteins that are important for membrane-tethering or fulfill other regulatory functions during Z-ring maturation. Second, late-stage cell division proteins including peptidoglycan synthesis enzymes arrive at the future division site, which allow for the synthesis of septal peptidoglycan and finally cytokinesis $[125,126]$. In C. crescentus, assembly of the cytokinetic apparatus occurs in at least seven distinct steps, nonetheless, the time difference between the recruitment of early- and late-division proteins to the division site is comparable with the observations made for E. coli and B. subtilis [127]. The early-stage division proteins commonly arrive at the division site at approximately $25 \%$ progression of the cell cycle, which members differ depending on the bacterial species. For example, early-cell division proteins in B. subtilis include FtsZ, FtsA, SepF, ZapA and EzrA [126], while these are represented by FtsA, ZipA, ZapA, FtsE and FtsX in E. coli [125]. C. crescentus mostly encodes for the same early-division proteins found in E. coli, except for ZipA, but also involves further proteins such as FzlA, FzlC and DipI [127-129].

FtsA, an ATPase of the actin/Hsc70/hexokinase superfamily, is conserved among most bacterial species including E. coli, B. subtilis and $S$. aureus [130-132], emphasizing its central role in regulating the Z-ring. FtsA acts as a membrane anchor for FtsZ, as it interacts with the CTT region of FtsZ and concomitantly binds to the lipid bilayer via its C-terminal amphipathic helix [133-135]. Furthermore, FtsA forms actin-like protofilaments in an ATP-dependent manner [136-138] that can assemble into lipid-bound minirings and antagonize lateral interactions between FtsZ protofilaments [139-141]. It is hypothesized that FtsA minirings may guide FtsZ to form long, often parallel, but unbundled protofilaments, thereby influencing the higher order structure of FtsZ and divisome function [139]. Recent data suggest that by consuming ATP, FtsA may even reorganize liposome architecture upon the binding of ATP to recruit FtsZ [142]. Inactivation of FtsA in rod-shaped B. subtilis and E. coli causes filamentation of the 


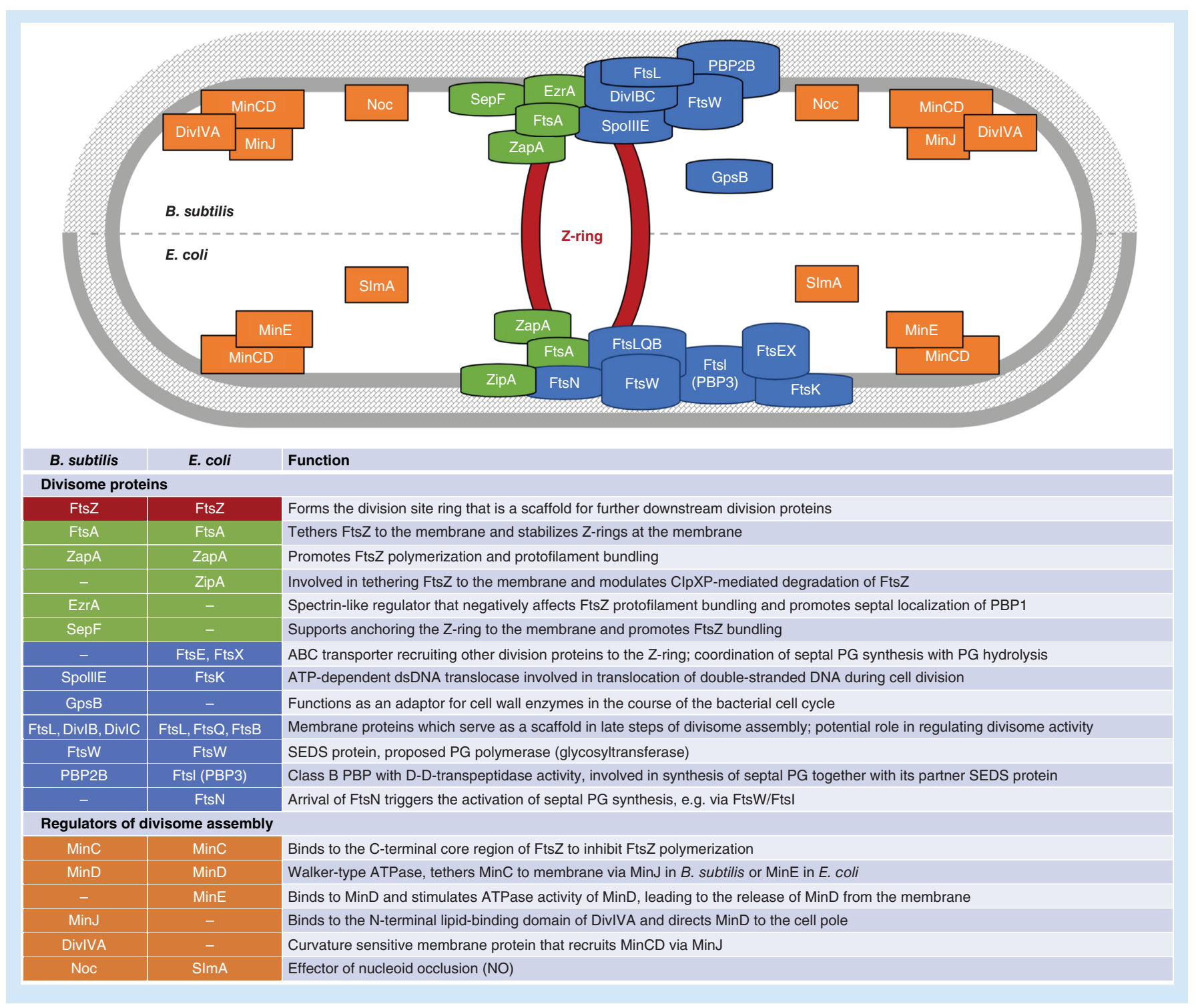

Figure 3. Divisome proteins of Bacillus subtilis and Escherichia coli. In B. subtilis and E. coli, cell division is initiated by the midcell localization of FtsZ and the formation of the Z-ring (in red), which is followed by the recruitment of early divisome proteins such as FtsA, EzrA, ZapA, SepF and ZipA (in green) that contribute to Z-ring dynamics and membrane tethering. Late-phase divisome proteins (in blue), including the penicillin-binding proteins (PBPs) and FtsW, contribute to septum formation by redirecting peptidoglycan (PG) synthesis toward cross-wall growth. Regulators of Z-ring positioning (in orange), such as the Min and NO systems, act to prevent the initiation of extra Z-rings at the newly formed cell pole or over the nucleoid, respectively.

bacterial cells [143-145]. Moreover, in the coccoid S. pneumoniae, depletion of FtsA results in swelling and eventually cell lysis that is accompanied by the dispersion of peptidoglycan synthesis, thus suggesting a dual role for $S$. pneumoniae FtsA in divisome assembly as well as peptidoglycan synthesis [146].

ZipA, which appears to be specific to $\gamma$-proteobacteria such as $E$. coli, tethers dynamic polymers of FtsZ to the cytoplasmic membrane by interacting with the CTT region of FtsZ [59,62,134,147]. ZipA has been assumed to regulate Fts $Z$ dynamics by supporting the bundling of Fts $Z$ protofilaments to stabilize the $Z$-ring. However, a recent report suggests that ZipA does not directly stimulate lateral interactions between FtsZ protofilaments, but acts via passive membrane attachment for FtsZ filaments as they treadmill [148]. Interestingly, gain of function mutants of FtsA, which are impaired for self-interaction, bypass the loss of the essential ZipA protein in E. coli, suggesting that self-interaction of FtsA competes with the ability of FtsA to recruit further downstream division proteins [149,150]. In this context, it has recently been confirmed that ZipA directly interacts with FtsA [151]. Also noteworthy, in addition 
to supporting Z-ring assembly via direct interaction with FtsZ, ZipA is assumed to prevent degradation of FtsZ by the bacterial protease ClpXP in E. coli via occupying the recognition signal for the unfoldase ClpX in the last 18 amino acid residues of FtsZ [59,152]. By doing so ZipA indirectly modulates the assembly/disassembly dynamics of the Z-ring via ClpXP in E. coli. In B. subtilis, which lacks a ZipA homolog, SepF acts as an additional membrane anchor that binds to the C-terminus of FtsZ resulting in stabilization of FtsZ protofilaments [63,153,154]. In vitro, SepF polymerizes into large rings that support the bundling of FtsZ protofilaments [155]. SepF is not essential for survival under normal growth conditions, but it is synthetically lethal when combined with either ezrA or fts $A$ deletion mutants $[153,154,156]$. In $S$. pneumoniae, a deletion of $\operatorname{sep} F$ results in elongated cells with septation defects and unconstricted $Z$-rings, indicating a role in the later steps of cell division rather than for anchoring $\mathrm{Fts} Z$ to the membrane [146]. C. crescentus also lacks a ZipA homolog, instead FzlC is assumed to anchor the Z-ring to the inner side of the cytoplasmic membrane, since it is capable to recruit FtsZ to membranes in vitro [157].

In addition to FtsA, SepF and ZipA, further early-stage division proteins modulate the dynamics of FtsZ protofilaments and Z-ring formation, such as ZapA, ZapB, ZapC, ZapD and EzrA. The widely conserved small coiled-coil protein ZapA binds to FtsZ to affect GTPase activity in vitro and to promote bundling of FtsZ protofilaments [158-160], and by doing so even reverses the inhibitory effects of the FtsZ polymerization antagonist SulA in E. coli [161]. Noteworthy, the cellular concentration of ZapA roughly equals that of FtsZ, and in vitro pelleting assays revealed an equal stoichiometry between both proteins as well $[162,163]$, which may suggest a more intimate relationship between both proteins. In this context, overproduction of ZapA rescues the defects of an FtsZ mutant in B. subtilis, which is impaired in lateral interactions between protofilaments [67], supporting a role for ZapA as a cross-linking and bundling factor for FtsZ. In E. coli, ZapA further recruits ZapB to form FtsZ-independent structures at the division site that are assumed to link Z-ring assembly to the terminus region of the chromosome [106,164]. In addition, ZapC and ZapD interact with FtsZ to promote bundling between FtsZ polymers. To do so, ZapD binds to the CTT region of FtsZ [64,165], whereas ZapC interacts with the GTPase core region [65]. In C. crescentus, however, ZapA did not show any effects on FtsZ bundling or GTPase activity, but appears to interact with ZauP to stabilize Z-ring formation at midcell via a mechanism that is independent of FtsZ polymer bundling [166]. Of note, Zap proteins are nonessential in their respective organisms under normal growth conditions, but the depletion of multiple Zap proteins or their deletion in combination with other divisome proteins, may cause severe cell division defects or are synthetically lethal $[64,158,167,168]$.

In E. coli and C. crescentus, the ATP-binding cassette transporter-like complex FtsEX represents early divisome proteins, which aid in recruiting further downstream division proteins. Additionally, FtsEX play a role in activating both the divisome via FtsA to allow for septal peptidoglycan synthesis [169], as well as peptidoglycan hydrolases to regulate cell wall hydrolysis at the division site [169-171]. In contrast, FtsEX in B. subtilis appear to control peptidoglycan hydrolases involved in cell elongation, while both proteins are not involved in cell wall hydrolysis at the septum [172,173].

In B. subtilis, the integral membrane protein EzrA, which is conserved among low G/C Gram-positive bacteria, comprises an $\mathrm{N}$-terminal transmembrane spanning helix as well as a large cytoplasmic domain that is assumed to connect bacterial cytoskeletal elements with membrane-associated proteins analogous to the function of eukaryotic spectrins [174]. EzrA interacts with FtsZ via the CTT/CTV regions [50], as well as with other cell division proteins such as PBP1 and GpsB $[175,176]$ to exert both negative as well as positive effects on the individual divisome proteins. On the one hand, EzrA negatively affects FtsZ protofilament bundling and the deletion of ezrA results in extra Z-rings that localize at the future division plane and at the polar regions of the cell [49,177]. On the other hand, EzrA promotes the septal localization of PBP1 (or PonA), a bi-functional glycosyltransferase-transpeptidase peptidoglycan synthase that contributes to cell wall synthesis at the septum [175]. In addition, the deletion of ezrA results in a delay of Z-ring constriction and cells are significantly longer compared with wild-type cells. Moreover, combining an $e z r A$ deletion with single deletions of other divisome proteins, such as ZapA or SepF, which individually do not significantly affect growth, results in severe growth defects $[153,158]$. In S. aureus, EzrA is essential and it was shown to interact with FtsZ, SepF as well as with GpsB, PBP2 and RodA to coordinate cell division with peptidoglycan synthesis [178].

In the context of antibiotic action, it is further noteworthy that the deletion of ezrA in B. subtilis leads to tetracycline hypersensitivity even in the presence of the tetracycline efflux pump TetA [179], indicating an effect that appears to be unrelated to the protein translation inhibiting activity of tetracycline. While the explicit reason for the tetracycline hypersensitivity has remained unclear so far, it is hypothesized that an accumulation of tetracycline 
molecules into the lipid bilayer destabilizes certain membrane proteins [179], which may be synthetically lethal in combination with a deletion of ezrA.

After a temporal delay, late-stage divisome proteins are recruited to the Z-ring, which among others include FtsK, FtsQ, FtsL, FtsB, FtsW, FtsI (or PBP3) and FtsN in E. coli ${ }_{[124,180]}$ or PBP2b, FtsL, DivIB, DivIC, GpsB, FtsW and DivIVA in B. subtilis [126]. These proteins either function in peptidoglycan synthesis or in the coordination of cytokinesis with other cellular processes. In $E$. coli for example, the membrane-bound DNA-translocase FtsK consists of two functionally distinct domains that work together to coordinate the divisome with the late stages of chromosome segregation $[124,181,182]$. Similarly, DivIVA may play a role in linking chromosome segregation and cell division in $S$. aureus, since an increased number of anucleate cells has been observed in mutants with double deletions of divIVA and either $d n a K$ or $s m c$ [183]. Regarding peptidoglycan synthesis, a ternary complex of the bitopic integral membrane proteins FtsQ, FtsL and FtsB in E. coli (as well as their homologs DivIB, FtsL and DivIC in B. subtilis) acts as a scaffold for the recruitment of other cell division proteins to regulate the activity of the divisome [184-186], thereby connecting the developing divisome with components of the peptidoglycan synthesis machinery (e.g., FtsW, FtsI/PBP3, PBP2b, GpsB) [126,187-194]. To complete cytokinesis, late-stage division proteins further trigger the constriction of the divisome, such as DipI in C. crescentus [129] or FtsN in E. coli [185, 195, 196], with the latter organized in large, discrete macromolecular assemblies, representing distinct FtsZ-rings and Fts $\mathrm{N}$-rings, rather than one super-complex [197].

\section{Targeting FtsZ with antimicrobial agents}

The previous sections highlighted the complexity of cell division, a central and vital process to many bacteria, which emerges to be tightly regulated by conserved and often interacting effectors. Nonetheless, most cell division inhibitors described to date act via FtsZ, either by interfering with its GTPase activity or the assembly/disassembly dynamics of the Z-ring, as well as by destabilizing the structural integrity of Fts Z leading to its degradation (Table 1).

The vast majority of cell division inhibitors bind to the core region of Fts $Z$ and modulate its GTPase activity, which is crucial for the assembly and constriction of the Z-ring. For example, in silico analyses of potential competitors of GTP led to the discovery of gallates and derivatives thereof, such as compound 28, with antimicrobial activity against methicillin-resistant $S$. aureus (MRSA) and Listeria monocytogenes in the low $\mu \mathrm{M}$ range. To do so, the compounds bind to Fts $Z$ with a dissociation constant $\left(K_{\mathrm{d}}\right)$ of $0.5 \mu \mathrm{M}$ without cross-targeting eukaryotic tubulin $\left(K_{\mathrm{d}}>100 \mu \mathrm{M}\right)$. As a consequence, gallates induce filamentation of $B$. subtilis cells, which is characterized by impaired Z-ring dynamics [198]. Similarly, alkyl gallates inhibit cell division via direct targeting of FtsZ and additionally permeabilize the bacterial membrane, thus exhibiting a dual mode of action [199]. Curcumin, a natural polyphenolic compound from Curcuma longa, exerts only moderate antimicrobial activity against $B$. subtilis and E. coli with MICs of about $100 \mu \mathrm{M}$ [200]. However, curcumin bioconjugates showed improved activity against several pathogens including staphylococci, streptococci and enterococci in the range of 2.5-20 $\mu \mathrm{M}$ [201]. Curcumin induces filamentation of rod-shaped bacteria and prevents Z-ring formation. By interacting with the GTP-binding pocket of FtsZ, curcumin increases FtsZ GTPase activity and blocks the assembly and bundling of FtsZ protofilaments. The latter may be explained by an increased GTP hydrolysis that favors the reconversion of FtsZ protofilaments into monomers [200,202]. Although derivatization of curcumin led to the identification of promising analogs regarding antimicrobial activity against clinically relevant enterobacteria [203], several hurdles prevent the use of curcumin as a therapeutic agent [204] such as restricted bioavailability [205] as well as potential cytotoxicity, since curcumin binds to eukaryotic tubulin at concentrations of $0.1 \mu \mathrm{M}$ (physiological) or higher, and results in the depolymerization of microtubules [206]. It is therefore not surprising that curcumin is known to act as an anticancer and anti-inflammatory agent as well [201]. However, further derivatization and computational docking studies might help to explore structural mimetics and more potent derivatives with selective antibacterial activity. Chrysophaentins comprise eight macrocyclic natural products, designated chrysophaentin $\mathrm{A}-\mathrm{H}$ that are produced by the chrysophyte marine alga Chrysophaeum taylorii, of which chrysophaentin A exhibits antibacterial activity against MRSA and vancomycin-resistant enterococci (VRE) [207]. Chrysophaentin A induces mislocalization of FtsZ in B. subtilis and in permeabilized E. coli cells, which is most probably due to a decreased level of FtsZ GTPase activity $\left(\mathrm{IC}_{50}\right.$ SaFtsZ, $67 \mu \mathrm{M}$; $\mathrm{IC}_{50}$ EcFtsZ, $10 \mu \mathrm{M}$ ) [208]. Computational docking studies identified the binding region of chrysophaentins at the GTP-binding site, explaining its mode of action by direct competition with GTP for the binding to FtsZ. Noteworthy, chrysophaentin A appears to have a higher specificity for FtsZ over tubulin, potentially allowing a more selective use of these compounds as antimicrobial agents [207]. Vanillin is appreciated for its antimicrobial properties as a food preservative [209]. Derivatives of vanillin are active against $E$. 
Table 1. Chemical structures, modes of action and antibacterial activities of FtsZ inhibitors.

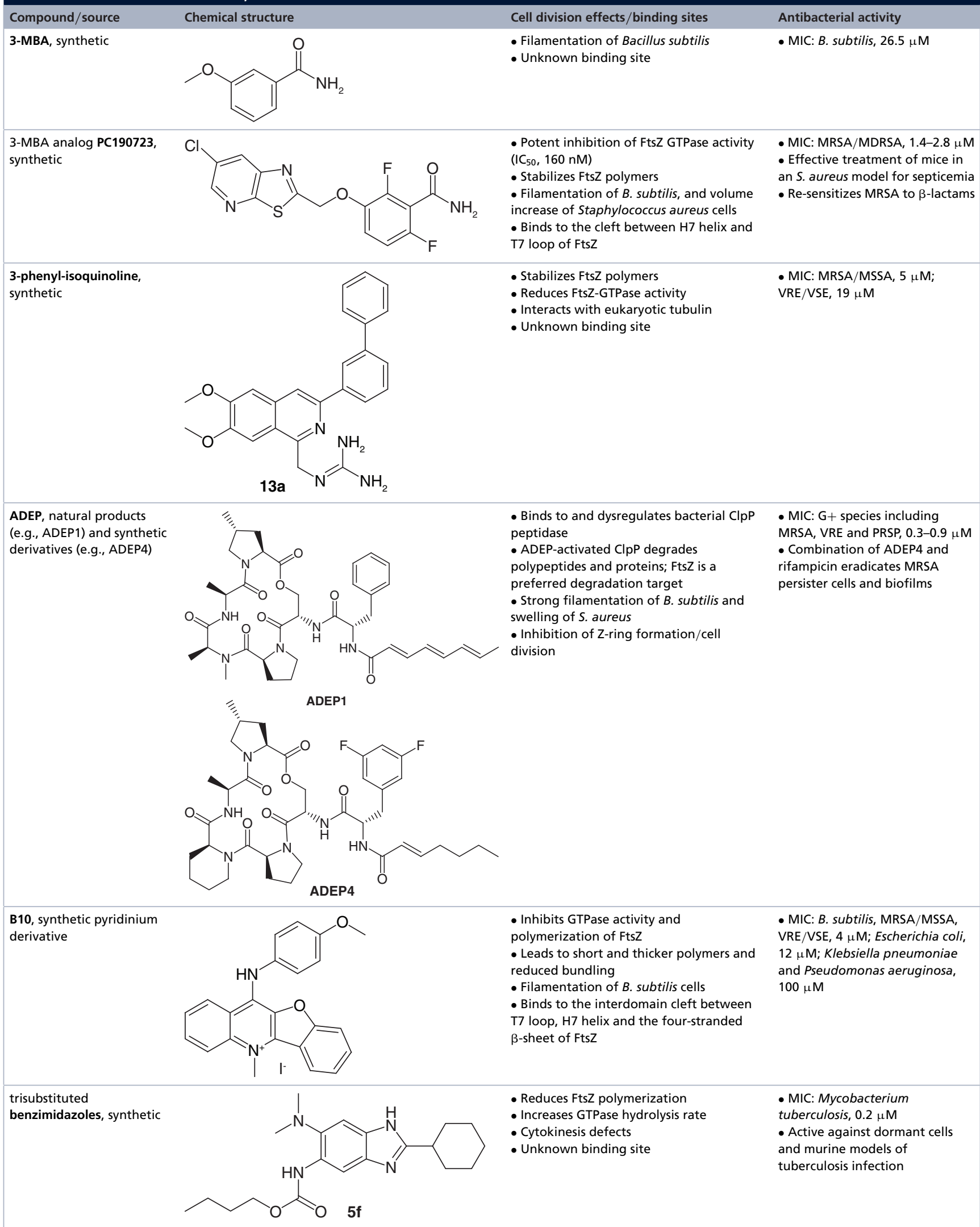

G+: Gram-positive bacteria; G-: Gram-negative bacteria; MDR: multidrug-resistant; MIC $_{50}$ : Lowest concentration of the antibiotic at which $50 \%$ of the bacteria are inhibited; MRSA: Methicillin-resistant S. aureus; MSSA: Methicillin-susceptible S. aureus; PRSP: Penicillin-resistant S. pneumoniae; VRE: Vancomycin-resistant enterococci; VSE: Vancomycin-susceptible enterococci. 
Table 1. Chemical structures, modes of action and antibacterial activities of FtsZ inhibitors (cont.).

\begin{tabular}{|c|c|c|c|}
\hline Compound/source & Chemical structure & Cell division effects/binding sites & Antibacterial activity \\
\hline $\begin{array}{l}\text { berberine, plant natural } \\
\text { product }\end{array}$ & & $\begin{array}{l}\text { - Inhibits FtsZ polymerization }\left(\mathrm{IC}_{50}\right) \text { : E. coli, } \\
10 \mu \mathrm{M} ; \mathrm{S} \text {. aureus, } 200 \mu \mathrm{M} \text {; and B. anthracis, } \\
63 \mu \mathrm{M} \\
\text { - Reduces GTPase activity } \\
\text { - Leads to filamentation and impairment of } \\
\text { Z-ring formation } \\
\text { - Binds to the hydrophobic pocket in the } \\
\text { GTP binding region of FtsZ }\end{array}$ & $\begin{array}{l}\text { - MIC: G+ and G- species, } \\
>190 \mu \mathrm{M}\end{array}$ \\
\hline $\begin{array}{l}\text { berberine analog } \\
\text { dibenzo[a,g]quinolizin-7- } \\
\text { ium, } \\
\text { synthetic }\end{array}$ & & $\begin{array}{l}\text { - Stimulates FtsZ polymerization } \\
\text { - Unknown binding site }\end{array}$ & $\begin{array}{l}\text { - MIC: MRSA/MRSA, } 0.9 \mu \mathrm{M} \text {; } \\
\text { VRE/VSE, } 3.7 \mu \mathrm{M}\end{array}$ \\
\hline $\begin{array}{l}\text { BT-benzo-29, synthetic } \\
\text { phenolic compound }\end{array}$ & & $\begin{array}{l}\text { - Filamentation of } B \text {. subtilis at sublethal } \\
\text { concentrations }(1 \mu \mathrm{M}) \\
\text { - Perturbs Z-ring dynamics } \\
\text { - Delocalization of divisome proteins such } \\
\text { as FtsZ, FtsA, ZapA and SepF } \\
\text { - Inhibits BsFtsZ polymerization }\left(\mathrm{IC}_{50} \text {, }\right. \\
26 \pm 3 \mu \mathrm{M}) \\
\text { - Reduces FtsZ GTPase activity ( }\left(\mathrm{I}_{50} \text {, }\right. \\
15.3 \pm 3.2 \mu \mathrm{M}) \\
\text { - Binds to the C-terminal domain in the } \\
\text { vicinity of the T7 loop }\end{array}$ & $\begin{array}{l}\text { - MIC: B. subtilis, } 4.2 \pm 0.7 \mu \mathrm{M} \text {; } \\
\text { Mycobacterium smegmatis, } \\
1.6 \pm 0.4 \mu \mathrm{M}\end{array}$ \\
\hline $\begin{array}{l}\text { CCR-11, synthetic phenolic } \\
\text { compound }\end{array}$ & & $\begin{array}{l}\text { - Inhibits BsFtsZ polymerization } \\
\text { - Reduces FtsZ GTPase activity } \\
\text { - Filamentation of B. subtilis at } 2.5 \mu \mathrm{M} \\
\text { - Binds to a cleft near the T7 loop }\end{array}$ & $\begin{array}{l}\text { - MIC: B. subtilis, } 3 \mu \mathrm{M} ; M \text {. } \\
\text { smegmatis, } 4 \mu \mathrm{M} \text { (determined by } \\
\text { agar dilution method) }\end{array}$ \\
\hline $\begin{array}{l}\text { chrysophaentin A, natural } \\
\text { product }\end{array}$ & & $\begin{array}{l}\text { - Inhibits FtsZ GTPase activity (EcFtsZ IC } \mathrm{C}_{50} \text {, } \\
9.9 \pm 2.5 \mu \mathrm{M} ; \text { SaFtsZ IC } \mathrm{C}_{50}, 67 \pm 13 \mu \mathrm{M} \text { ) } \\
\text { - Mislocalization of FtsZ in } B \text {. subtilis and } \\
\text { permeabilized } E \text {. coli cells } \\
\text { - Binds to the GTP-binding site }\end{array}$ & $\begin{array}{l}\text { - } \mathrm{MIC}_{50} \text { : S. aureus, } 2.2 \pm 1.0 \mu \mathrm{M} ; \\
\text { MDR S. aureus, } 1.9 \pm 0.6 \mu \mathrm{M} ; \\
\text { VRE, } 4.3 \pm 1.2 \mu \mathrm{M}\end{array}$ \\
\hline
\end{tabular}


Table 1. Chemical structures, modes of action and antibacterial activities of FtsZ inhibitors (cont.).

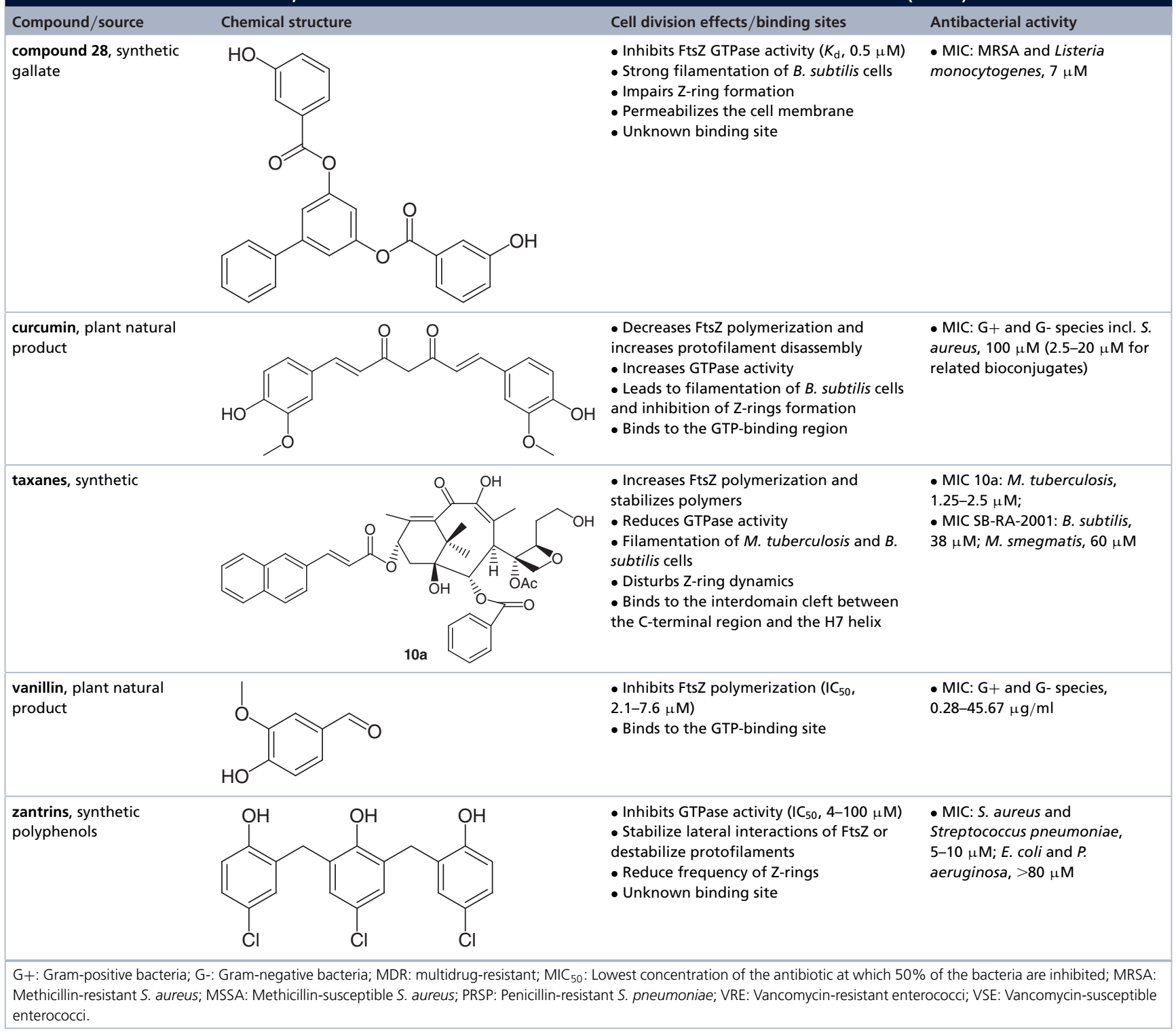

coli in the sub- $\mu \mathrm{g} / \mathrm{ml}$ range and inhibit GTPase activity of FtsZ with an $\mathrm{IC}_{50}$ of $2.1 \mu \mathrm{M}$ [210]. Amikacin, a broadspectrum semi-synthetic aminoglycoside antibiotic, which is known to inhibit protein biosynthesis by preventing the translocation of peptidyl-tRNA, shows a second mode of action at sublethal concentrations $(6.8 \mu \mathrm{M})$ by inhibiting cell division without affecting chromosome dynamics. Here, amikacin causes a reduction of Z-rings accompanied by an elongation of $E$. coli cells [211], which is most probably due to the binding of amikacin to the GTP-binding site of FtsZ [212]. Zantrins represent a group of five diverse phenolic compounds that affect the GTPase activity of FtsZ $\left(\mathrm{IC}_{50} 4-100 \mu \mathrm{M}\right)$ and either destabilize FtsZ protofilaments (zantrins Z1, Z2 and Z4) or lead to hyperstability of FtsZ protofilaments by supporting lateral interactions (zantrins Z3 and Z5). In vivo, zantrins reduce the frequency of Z-ring formation in $E$. coli but do not induce filamentation in cells, except for Z5. Due to their rather weak antimicrobial activity with MICs in the range of 66-98 $\mu \mathrm{M}$ for zantrins Z1-Z4 against Gram-positive bacteria, zantrins require further optimization to yield more promising lead compounds [213]. Taxanes are well-known therapeutic anticancer agents that act on eukaryotic tubulin, which hampers their immediate use as antimicrobial agents. However, derivatization of taxanes produced noncytotoxic and more potent antitubercular compounds with MICs in the range of $1.25-2.5 \mu \mathrm{M}$ against multidrug-resistant $M$. tuberculosis, such as compound 10a that stabilizes FtsZ polymerization and induces filamentation of $M$. tuberculosis cells [214]. In silico data suggest that taxanes bind 
to the interdomain cleft between the C-terminal region and the $\alpha$-helix H7 of FtsZ [215]. Berberine, a natural isoquinoline-type alkaloid obtained from the widely distributed Berberidaceae and other plant families [216], perturbs Z-ring dynamics, decreases the number of Z-rings per cell unit and induces filamentation of E. coli cells [217,218]. Berberine binds to a hydrophobic pocket of FtsZ, which overlaps the GTP region, with a $K_{\mathrm{d}}$ of $0.023 \mu \mathrm{M}$ [218], reduces GTPase activity, and disrupts the protofilament architecture of FtsZ in vitro, thereby preventing FtsZ polymerization [218-220]. Due to its anti-Fts $Z$ activity, berberine has been the subject of various derivatization programs, some of which yielded improved derivatives that inhibit the growth of MRSA and VRE with MICs in the range of $0.5-2 \mu \mathrm{g} / \mathrm{ml}$, respectively [221,222]. Berberine and the benzophenanthridine alkaloid sanguinarine share a pyridinium core from which synthetic quaternary pyridinium and 5-methylphenantridium derivatives were designed [223,224]. For example, derivative B10 displays broad-spectrum antimicrobial activity against important pathogens including MRSA, VRE, Klebsiella pneumoniae, P. aeruginosa and E. coli with MICs in the range of $2-48 \mu \mathrm{g} / \mathrm{ml}(4-100 \mu \mathrm{M})$ [223]. Moreover, combination of the ring cores of berberine and sanguinarine led to the design and synthesis of 3-phenyl-isoquinoline derivatives, which reduce the GTPase activity of SaFtsZ and stabilize polymers in vitro. Some of the synthetic derivatives were effective against MRSA and VRE (MIC of $1-8 \mu \mathrm{g} / \mathrm{ml}$ ) and showed only low cytotoxicity against mammalian cells [225]. Interestingly, addition of an aryl group in either position two or 12 improved the antimicrobial activity of the synthetic berberine analog dibenzo[a,g]quinolizin-7ium, which in contrast to its natural counterpart, stimulates SaFtsZ polymerization [221]. Noteworthy, antimicrobial activity of berberine could also be increased in combination with $5^{\prime}$-methoxyhydnocarpin, a natural compound that inhibits the NorA eflux pump of $S$. aureus [226]. Furthermore, there are reports on synergistic effects of berberine in combination with penicillin, oxacillin, erythromycin, azithromycin, cefazolin, levofloxacin and clindamycin against Gram-positive bacteria including MRSA [227,228]. Also noteworthy, berberine inhibits the GTPase activity of FtsZ from Wolbachia, an obligate bacterial endosymbiont of filarial nematode parasites, and reduces the motility and reproduction of the filarial nematode Brugia malayi in vitro [229], thus validating FtsZ inhibition as a new approach to control and treat filarial infections.

The compounds described so far bind to or at least near the GTP-binding site of FtsZ. However, targeting the conserved GTP-binding site may principally bear a higher risk for cross-targeting eukaryotic tubulin and thus provoke cytotoxicity in human cells, a notion that is supported by numerous compounds with known pharmacological side effects, such as plumbagin [230,231], viriditoxin [232,233], sanguinarine [234-236] or doxorubicin [235,237,238]. Thus, compounds with binding sites other than the conserved GTP-binding region may be favorable. In this context, screening a library of rhodanine compounds for a filamentation phenotype of $B$. subtilis identified compound CCR-11, which binds to FtsZ with a $K_{\mathrm{d}}$ of $1.5 \mu \mathrm{M}$ and inhibits FtsZ polymerization as well as GTPase activity in vitro [239]. Furthermore, CCR-11 inhibits the growth of B. subtilis and Mycobacterium smegmatis with MICs of 3 and $4 \mu \mathrm{M}$, respectively, disturbs Z-ring formation, and causes delocalization of FtsZ in whole cells. Notably, CCR-11 showed no cytotoxic activity against HeLa cells in that study. According to in silico docking simulations, interestingly, CCR-11 rather binds to a cleft near the T7 loop of FtsZ than to the GTP-binding site [239]. Trisubstituted benzimidazoles represent a group of promising antitubercular lead compounds, which inhibit the growth of several clinical isolates with MICs in the range of $0.39-6.1 \mu \mathrm{g} / \mathrm{ml}$. In vitro, these compounds inhibit the polymerization of MtbFtsZ by stimulating the GTPase activity of FtsZ in a dose-dependent manner [240]. Structure-activity relationship (SAR) analyses and drug development programs led to the discovery of derivatives with improved antibacterial activity in vitro (e.g., compound $5 \mathrm{f}$ with an MIC of $0.06 \mu \mathrm{g} / \mathrm{ml}$ ) [241] as well as in dormant cells and in murine models of tuberculosis infection [242,243]. The benzimidazole derivative BT-benzo-29 binds to FtsZ with a $K_{\mathrm{d}}$ of $24 \mu \mathrm{M}$ (tubulin, $K_{\mathrm{d}} 152 \mu \mathrm{M}$ ) and reduces GTPase activity of BsFtsZ with an $\mathrm{IC}_{50}$ of $15 \mu \mathrm{M}$. In whole cells, BT-benzo-29 induces filamentation of B. subtilis at rather low concentrations $(1 \mu \mathrm{M})$ and inhibits growth with an $\mathrm{MIC}_{50}$ (MIC to inhibit proliferation by $50 \%$ ) of $4.2 \mu \mathrm{M}$ for B. subtilis and $1.6 \mu \mathrm{M}$ for M. smegmatis. Colocalization studies indicated perturbed Z-ring dynamics and a concomitant delocalization of other divisome proteins, such as FtsA, ZapA and SepF. Noteworthy, in silico analysis also proposed binding of BT-benzo-29 in the vicinity of the T7 loop of the C-terminal domain [244]. In this context, further effectors of Fts Z have been predicted to bind in the T7 loop region, thereby interfering with FtsZ function and preventing cell division, such as cinnamaldehyde, coumarins and phenylpropanoids [245-249], which may thus represent a promising strategy to avoid cross-targeting of tubulin and reduce cytotoxic effects in eukaryotic cells.

Thinking along these lines, a group of synthetic benzamide derivatives (including 3-methoxybenzamide, 3MBA) induces filamentation and cell death in B. subtilis, which is abrogated in ftsZ-deficient mutants [250]. SARbased derivatization of 3-MBA yielded more than 500 analogs, among them PC190723 with strong antibacterial 
(A)
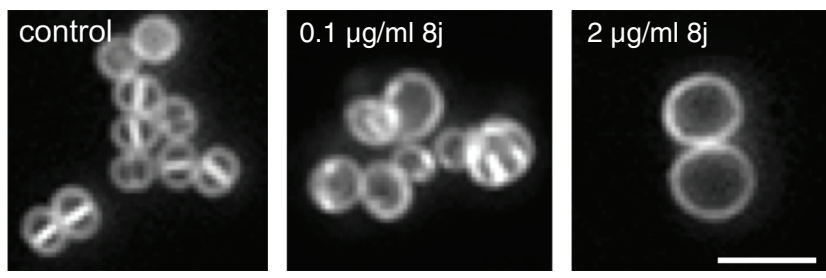

(B)

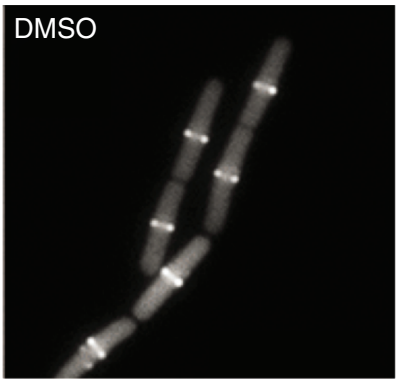

(C)

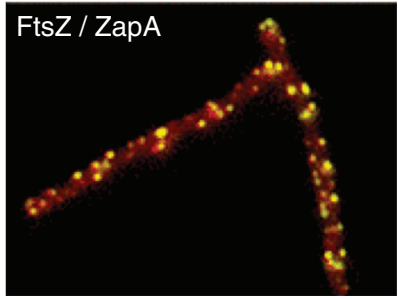

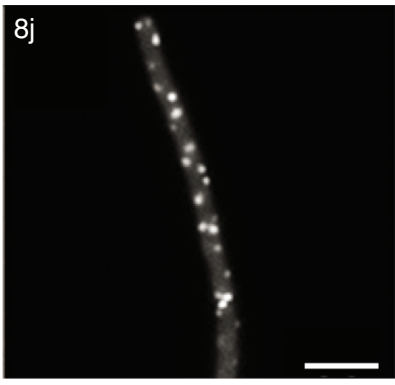

FtsZ / DivlC

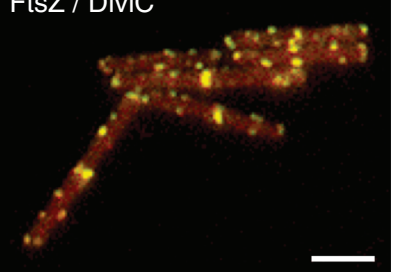

Figure 4. Deregulation of Z-ring formation by the PC190723-analog 8j. (A) 8j treatment leads to abnormal cell division in Staphylococcus aureus cells. S. aureus strain RN4220 was grown in the absence and presence of 0.1 or 2 $\mu \mathrm{g} / \mathrm{ml} 8 \mathrm{j}$. Cell membranes were stained with FM5-95. Scale bar, $3 \mu \mathrm{m}$. (B) Mislocalization of FtsZ in 8j-treated Bacillus subtilis cells. Fluorescence microscopy images of B. subtilis strain 2020 (GFP-FtsZ) show that 8j inhibits FtsZ localization and results in the formation of abnormal discrete foci throughout the cell, thereby preventing regular cell division. Scale bar, $3 \mu \mathrm{m}$. (C) Colocalization of FtsZ-CFP with either YFP-ZapA (left image) or YFP-DivIC (right image), indicated by yellow color, shows that downstream division proteins assemble at FtsZ foci in 8j-treated $B$. subtilis cells. Scale bar, $3 \mu \mathrm{m}$.

(A) Images adapted from [256], reprinted with permission from Wiley.

(B) Images adapted from [256], reprinted with permission from Wiley.

(C) Images adapted from [256], reprinted with permission from Wiley.

activity against $S$. aureus including MRSA with MICs in the range of $0.5-1 \mu \mathrm{g} / \mathrm{ml}(1.4-2.8 \mu \mathrm{M})$ as well as in in vivo murine models of $S$. aureus septicemia [251,252]. PC190723 significantly reduces the GTPase activity of FtsZ in a dose-dependent manner $\left(\mathrm{IC}_{50}\right.$ value of $\left.0.16 \mu \mathrm{M}\right)$. To do so, PC190723 binds to a cleft that is formed by the $\alpha$-helix H7, the T7 loop and the C-terminal four-stranded $\beta$-sheets of FtsZ, and importantly, no interference with eukaryotic tubulin has been observed in vitro [252]. Follow-up studies revealed an interesting nature of PC190723, as unlike most other FtsZ inhibitors, the effect of PC190723 involves stabilization of FtsZ polymers rather than destabilization, which consecutively halts the dynamics and functionality of FtsZ [253,254]. Accordingly, PC190723 and derivatives thereof, such as compound $8 \mathrm{j}$, lead to the formation of multiple rings and arcs of FtsZ in $S$. aureus (Figure 4A) as well as twisted septa and abnormal discrete foci of FtsZ at the cell poles and over the nucleoid in B. subtilis cells (Figure 4B) $[252,255,256]$. Noteworthy, such foci of FtsZ remain active and dynamic in terms of FtsZ turnover and still recruit further cell division proteins that interact with FtsZ (Figure 4C) [256]. Of note, fluorescent probes of PC190723 have been shown to change the fluorescence anisotropy after binding to previously polymerized FtsZ [257]. This finding supports the idea of an open conformation of FtsZ in the polymerized state as discussed above, while monomeric FtsZ adopts a closed conformation to which PC190723 appears unable to bind, thus demonstrating that antibiotics, in addition to their antimicrobial activity, may also function as tools to unravel 
(A) (1)
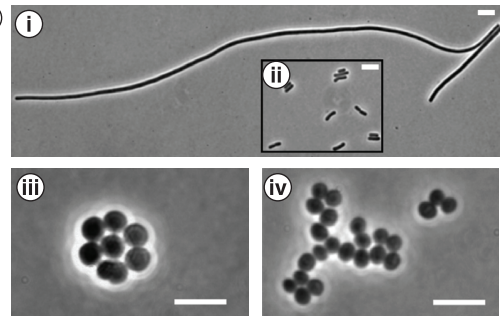

(v)

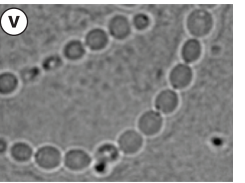

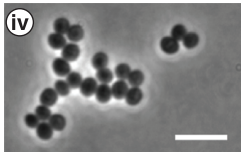

(vi)
西
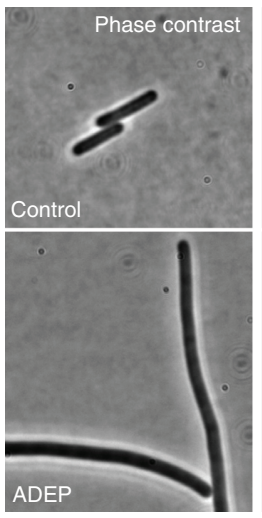
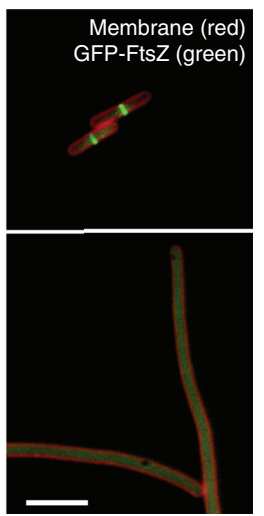
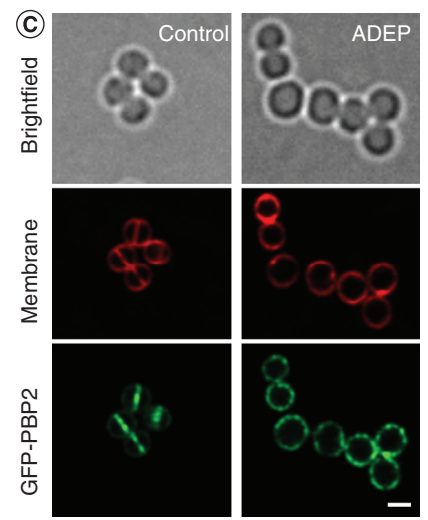

Figure 5. ADEP antibiotics inhibit cell division by activating bacterial ClpP peptidase to degrade FtsZ. (A) ADEP treatment results in an impressive filamentation of rod-shaped Bacillus subtilis 168 cells (i) as well as swelling of coccoid Staphylococcus aureus HG001 (iii) and Streptococcus pneumoniae G9A cells (v) compared with untreated control cells (ii, iv, and vi, respectively), thus indicating an inhibition of cell division. Scale bars, $5 \mu \mathrm{m}$. (B) Delocalization of GFP-FtsZ in ADEP-treated B. subtilis 2020 cells (lower panel), in contrast to normal Z-ring assembly in untreated cells (upper panel), leads to an inhibition of Z-ring/septum formation and finally cell division as indicated by the filamentous growth after prolonged ADEP treatment. Scale bar, $5 \mu \mathrm{m}$. (C) Fluorescence microscopy images show the delocalization of the divisome member PBP2 away from the septum to the cell periphery of S. aureus as a consequence of FtsZ degradation. Scale bar, $1 \mu \mathrm{m}$.

(A) Images reprinted from [265].

(B) Images reprinted from [265].

(C) Images adapted from [266] reprinted with permission from Elsevier.

general principles of bacterial cell biology. Further optimization of PC190723 yielded 'compound 1' and its succinate prodrug 'compound 2', which exhibit improved pharmacokinetic properties and superior antimicrobial activities toward pathogenic bacteria [258]. Novel derivatives of PC190723, such as TXY541, TXA709 or compound 9, resolve low bioavailability, are effective in animal models of severe staphylococcal infection and exert low cytotoxicity in mammalian cell lines [259-261]. Also, these derivatives exhibit superior metabolic and pharmacokinetic properties, improved in vivo antibacterial activity against MRSA [260], as well as an extended antibacterial spectrum regarding mycobacteria [261]. Moreover, PC190723 and derivatives thereof synergize with imipenem, cefdinir or cefuroxime by re-sensitizing MRSA to $\beta$-lactam antibiotics [255,262,263], for example, leading to a threefold reduction of the TXA709 oral dose required for efficacy. Since the septal localization of PBP2, which function is essential in MRSA, depends on FtsZ, the observed synergistic activity is most probably based on the concomitant delocalization of both drug targets. Resistance to PC190723 and TXA707 was reported to occur via mutations in the fts $Z$ gene with residues G196 and G193 being among the most prevalent [255,262]. Although several PC190723-resistant MRSA fts $Z$ mutants were also characterized by attenuated virulence [255], the use of PC190723/imipenem and TXA707/cefdinir combinations further proved beneficial in terms of resistance development as it markedly reduced the spontaneous frequency of PC190723- and TXA707-resistant mutants in MRSA, thereby addressing emerging issues related to suboptimal frequency of resistance associated with FtsZ-targeting benzamide antibiotics [255,262]. Recently, derivative TXA6101 has been described to even retain activity against MRSA that carry either G196S or G193D mutations in fts $Z$, which is assumed to result from the greater structural flexibility of TXA6101 relative to other PC190723 derivatives, thereby avoiding steric clashes with Ser196 and Asp193 [264]. Such potent synergistic action of PC190723 and derivatives with $\beta$-lactam antibiotics validates FtsZ inhibition as a promising strategy for antibiotic combination therapy.

The antibiotic compounds mentioned so far all directly interact with FtsZ, albeit using different binding sites to modulate FtsZ function and finally inhibit cell division. However, in recent years, studies on a new class of antibiotic acyldepsipeptides, designated ADEP, revealed a new and unprecedented way of interfering with bacterial cell division by leading to the untimely degradation of FtsZ. At low inhibitory concentrations of ADEP, rodshaped B. subtilis cells grow into impressively long filaments, whereas coccoid $S$. aureus and S. pneumoniae cells start swelling (Figure 5A) [265,266]. Furthermore, septum formation and Z-ring assembly is rapidly inhibited in treated cells, leading to the mislocalization of central divisome proteins (Figure 5B \& C). Under these conditions, 
biomass production and major cellular biosynthetic processes proceed unaffected [265], thus pointing at a potential target that is intimately involved in cell division. However, quite the contrary, ADEP was identified to bind to and deregulate the function of the bacterial caseinolytic protease Clp [267-273]. Here, ADEP binding leads to an inhibition of all natural $\mathrm{Clp}$ functions by abrogating the interaction of the proteolytic core $\mathrm{ClpP}$ with regulatory Clp-ATPases, such as ClpX or ClpC [270,271,273]. At the same time, ADEP activates the core ClpP for uncontrolled proteolysis of non-native protein substrates $[270,271,274]$. For further details on the deregulation of Clp protease by $\mathrm{ADEP}$ and other compounds, we kindly refer the reader to a recent comprehensive review on this topic [275]. In fact, ClpP activation by ADEP leads to the preferred and rapid degradation of FtsZ in ADEP-treated cells as well as in vitro [265], thereby explaining the observed phenotype of cell division inhibition that eventually leads to bacterial cell death. Noteworthy, at higher ADEP concentrations, ADEP-treated cells remain shorter and biomass production ceases, indicating an increased degradation of additional targets by ADEP-ClpP in the bacterial cell [266,276], which finally leads to suicide of the bacteria via self-digestion. Very recent data revealed the molecular basis for the preferred degradation of FtsZ by ADEP-ClpP. It emerged that ADEP-ClpP preferably attacks the N-terminus of FtsZ, which leads to the unfolding and subsequent degradation of the Fts $Z \mathrm{~N}$-terminal domain, thus indicating that the protein fold of Fts $Z$ appears to be more flexible than previously expected [276]. The natural product ADEP1 is produced by Streptomyces hawaiiensis NRRL 15010 and already shows promising antibiotic activity against Grampositive bacteria (S. aureus MIC of $6.3 \mu \mathrm{g} / \mathrm{ml}, 8.8 \mu \mathrm{M}$ ) [267,277] which was significantly improved by chemical engineering and total synthesis of new synthetic derivatives, such as ADEP4, with enhanced chemical and metabolic stability [278-281]. For example, ADEP4 is exceptionally potent to kill Gram-positive pathogens with MICs in the sub- $\mu \mathrm{g} / \mathrm{ml}$ range, including MRSA (MIC $=0.05 \mu \mathrm{g} / \mathrm{ml}, 0.065 \mu \mathrm{M})$ and vancomycin-resistant enterococci (VRE; $\mathrm{MIC}=\leq 0.01 \mu \mathrm{g} / \mathrm{ml}, 0.013 \mu \mathrm{M})[267,282]$. Furthermore, ADEP4 shows impressive efficacy in rodent models of staphylococcal infections, which was superior to that of the marketed antibiotic linezolid [267]. In combination with rifampicin, ADEP4 even eradicates persister cells in a chronic biofilm infection [283]. In addition, ADEPs are antibacterially active against streptococci [267], clostridia [284], mycobacteria [273,285], Wolbachia endobacteria [286] and even against Gram-negative Neisseria meningitidis [280]. However, due to the molecular size of ADEP, it is commonly too large to cross the outer membrane of Gram-negative bacteria, which mostly limits the use of ADEP to Gram-positives. Furthermore, its unprecedented mechanism of action combined with an impressive antibacterial activity in murine models of infection, ADEPs further proved noncytotoxic to eukaryotic cells in the concentration range that inhibits bacterial growth. Although ADEPs were shown to deregulate human mitochondrial ClpP in vitro [272], cytotoxicity did only occur at compound levels 100-1000-fold higher than the bacterial MIC [267,287,288], validating $\mathrm{ADEP}$ antibiotics as a promising new route for antibacterial intervention.

\section{Future perspective}

Bacterial cell division, coordinated by the central pacemaker protein FtsZ, may be compared with a well-adjusted clockwork with a defined set of gears to control and drive the division machine, in other words, parent cells have to coordinate a plethora of biosynthetic processes with the help of diverse divisome proteins to eventually divide and produce viable daughter cells. Due to its complexity and cross-regulative nature, further divisome proteins other than FtsZ may be envisioned as targets for antimicrobial or also antivirulence intervention, for example, since the deletion of $\min D$ in enterohemorrhagic E. coli (EHEC) caused reduced adherence to human epithelioid cervical carcinoma [289]. In recent years, especially the advances in fluorescence light microscopy, increasing both real and effective optical resolution, boosted the research in the field of bacterial cell biology and enabled vast progress to gain unprecedented insights into structures and complex dynamics of cellular systems. A profound understanding of the spatial dimensions and the dynamics of bacterial cell biology provides a basis for antibacterial drug development and thus aids in the discovery of new antibiotics that perturb such tightly regulated systems, potentially breaking the resistance of important human pathogens. This review summarized the mode of bacterial cell division along with a structurally diverse collection of cell division inhibitors, among which PC190723 and ADEP stand out as most promising leads for further exploration and the development of novel antimicrobials. Both compounds share resistance-breaking potential, suitable in vitro pharmaceutical properties and in vivo pharmacokinetic profiles, as well as substantial antibacterial activities in murine models of infection. Despite these promising assets, a major future task will be to explore suitable strategies to overcome the resistance problems that both antibiotic classes suffer from, since resistance may be conferred by mutations in FtsZ (for PC190723 [254,255]) or in ClpP (for ADEPs [267]). However, the synergistic activities of either PC190723 and derivatives with $\beta$-lactam antibiotics to combat MRSA or ADEP4 with rifampicin to eradicate staphylococcal persister cells represent promising approaches 
to tackle the resistance problem. Although resistance development may restrict their potential use to combination therapy against some pathogens, at least ADEP proved active against $M$. tuberculosis, an important human pathogen that strictly depends on ClpP for survival and expression of virulence factors during host infection [290], making inactivating mutations of ClpP in this pathogen at least unlikely. Thus, further compound optimization approaches to improve antibacterial activities against such pathogens are encouraged to develop both compound classes as antibiotic agents, which share promising mechanisms of action that impressively illustrate the broad and innovative repertoire that nature has invented to prevent bacterial growth by interfering with bacterial cell division.

\section{Executive summary}

Crystal structure, abundance \& functional regions of FtsZ

- FtsZ is the structural homolog of the eukaryotic cytoskeletal protein tubulin and consists of two major, self-folding protein domains, an N-terminal GTP-binding domain and a C-terminal domain.

- FtsZ and tubulin represent a distinct family of GTP-hydrolyzing enzymes.

- FtsZ is largely conserved across the domains Bacteria and Archaea, and it is assumed to be the ancestral progenitor of eukaryotic tubulin.

- The poorly conserved N-terminal peptide plays a role in cell division of cyanobacteria; however, it has not yet been assigned a function in Firmicutes and Proteobacteria.

- The highly conserved globular core region comprises the GTPase active site, functions as an interface for the head-to-tail association of FtsZ monomers into protofilaments, and it is involved in supporting lateral interactions of FtsZ protofilaments.

- The unstructured C-terminal linker (CTL) acts as a flexible tether to provide a defined distance from the bacterial membrane, where FtsZ is anchored via modulatory proteins.

- The short, conserved C-terminal tail (CTT) is the central hub for FtsZ-interacting divisome proteins.

- The C-terminal variable region (CTV) plays a role in lateral interactions of FtsZ protofilaments.

Positioning, assembly \& modulation of the Z-ring

- The Z-ring is a highly dynamic structure that is treadmilling around the division plane by bottom-end growth, constantly exchanging FtsZ subunits with the cytoplasmic pool.

- Z-ring positioning is controlled by negatively-acting factors, such as the NO- and Min-systems in Bacillus subtilis and Escherichia coli that prevent extra Z-rings over unsegregated nucleoids and at the cell pole region, respectively, or by positively-acting factors such as SsgAB in streptomycetes or MapZ/oriC in streptococci that mark the prospective division site.

- More than 35 divisome members have been identified so far, including early-stage proteins for membrane-tethering and Z-ring maturation as well as late-stage proteins involved in the synthesis of septal peptidoglycan and finally cytokinesis.

Targeting FtsZ with antimicrobial agents

- PC190723 and ADEP are among the most promising leads with resistance-breaking potential, suitable in vitro pharmaceutical properties and in vivo pharmacokinetic profiles, as well as substantial antibacterial activities in murine models of infection.

- PC190723 stabilizes FtsZ polymers and halts the dynamics and functionality of FtsZ, leading to the formation of multiple rings and arcs of FtsZ or abnormal discrete foci at the cell poles and over the nucleoid.

- ADEP antibiotics activate the bacterial peptidase CIpP for the untimely proteolytic digestion of FtsZ, thereby preventing Z-ring formation and thus cell division.

\section{Author contributions}

N Silber, CL Matos de Opitz and C Mayer drafted the manuscript; all authors prepared figures and tables; P Sass outlined, edited and finalized the manuscript.

\section{Acknowledgments}

We gratefully thank all team members of our department for their support and critical discussions.

Financial \& competing interests disclosure

The authors declare no competing interests. The authors appreciate funding by the Deutsche Forschungsgemeinschaft (DFG, German Research Foundation): Project-ID 398967434 (TRR 261, TP A02), Project-ID 32152271 (SFB766, TP A17), and support by infrastructural funding from Cluster of Excellence EXC 2124 Controlling Microbes to Fight Infections. PS further appreciates funding by the German Center for Infection Research (DZIF; TTU 09.815). The authors have no other relevant affiliations or financial 
involvement with any organization or entity with a financial interest in or financial conflict with the subject matter or materials discussed in the manuscript apart from those disclosed.

No writing assistance was utilized in the production of this manuscript.

\section{Open access}

This work is licensed under the Attribution-NonCommercial-NoDerivatives 4.0 Unported License. To view a copy of this license, visit http://creativecommons.org/licenses/by-nc-nd/4.0/

\section{References}

Papers of special note have been highlighted as: • of interest; $\bullet \bullet$ of considerable interest

1. Lutkenhaus JF, Wolf-Watz H, Donachie WD. Organization of genes in the ftsA-envA region of the Escherichia coli genetic map and identification of a new fts locus (ftsZ). J. Bacteriol. 142(2), 615-620 (1980).

2. Van De Putte P, Van Dillewijn J, Rörsch A. The selection of mutants of Escherichia coli with impaired cell division at elevated temperature. Mutat. Res. Fund. Mol. M. 1, 121-128 (1964).

3. Bi E, Lutkenhaus J. FtsZ ring structure associated with division in Escherichia coli. Nature 354, 161-164 (1991).

-. Breakthrough study shows that FtsZ forms a ring-like structure at the prospective division site, thereby boosting research in the field of bacterial cell biology.

4. De Boer P, Crossley R, Rothfield L. The essential bacterial cell division protein FtsZ is a GTPase. Nature 359(6392), 254-256 (1992).

5. Raychaudhuri D, Park JT. Escherichia coli cell-division gene fts $Z$ encodes a novel GTP-binding protein. Nature 359(6392), 251-254 (1992).

6. Mukherjee A, Dai K, Lutkenhaus J. Escherichia coli cell division protein FtsZ is a guanine nucleotide binding protein. Proc. Natl Acad. Sci. USA 90(3), 1053-1057 (1993).

7. Löwe J, Amos LA. Crystal structure of the bacterial cell-division protein FtsZ. Nature 391, 203-206 (1998).

-. Describes the first crystal structure of FtsZ, revealing its homology to eukaryotic tubulin.

8. Löwe J. Crystal structure determination of FtsZ from Methanococcus jannaschii. J. Struct. Biol. 124(2-3), 235-243 (1998).

9. Oliva MA, Trambaiolo D, Löwe J. Structural insights into the conformational variability of FtsZ. J. Mol. Biol. 373, 1229-1242 (2007).

10. Nogales E, Downing KH, Amos LA, Löwe J. Tubulin and FtsZ form a distinct family of GTPases. Nat. Struct. Mol. Biol. 5(6), 451-458 (1998).

11. Oliva MA, Cordell SC, Löwe J. Structural insights into FtsZ protofilament formation. Nat. Struct. Mol. Biol. 11, 1243-1250 (2004).

12. Raymond A, Lovell S, Lorimer D et al. Combined protein construct and synthetic gene engineering for heterologous protein expression and crystallization using Gene Composer. BMC Biotechnol. 9, 37 (2009).

13. Löwe J, Li H, Downing KH, Nogales E. Refined structure of alpha beta-tubulin at 3.5 A resolution. J. Mol. Biol. 313(5), 1045-1057 (2001).

14. Huecas S, Andreu JM. Polymerization of nucleotide-free, GDP- and GTP-bound cell division protein FtsZ: GDP makes the difference. FEBS Lett. 569(1-3), 43-48 (2004).

15. Bourne HR, Sanders DA, Mccormick F. The GTPase superfamily: conserved structure and molecular mechanism. Nature 349, 117-127 (1991).

16. Polekhina G, Thirup S, Kjeldgaard M, Nissen P, Lippmann C, Nyborg J. Helix unwinding in the effector region of elongation factor EF-Tu-GDP. Structure 4(10), 1141-1151 (1996)

17. Vaughan S, Wickstead B, Gull K, Addinall SG. Molecular evolution of FtsZ protein sequences encoded within the genomes of Archaea, Bacteria, and Eukaryota. J. Mol. Evol. 58, 19-39 (2004).

18. Kalman S, Mitchell W, Marathe R et al. Comparative genomes of Chlamydia pneumoniae and C. trachomatis. Nat. Genet. 21, 385-389 (1999).

19. Pilhofer M, Rappl K, Eckl C et al. Characterization and evolution of cell division and cell wall synthesis genes in the bacterial phyla Verrucomicrobia, Lentisphaerae, Chlamydiae, and Planctomycetes and phylogenetic comparison with rRNA genes. J. Bacteriol. 190, 3192-3202 (2008).

20. Stephens RS, Kalman S, Lammel C et al. Genome sequence of an obligate intracellular pathogen of humans: Chlamydia trachomatis. Science 282(5389), 754-759 (1998).

21. Nakabachi A, Yamashita A, Toh H et al. The 160-kilobase genome of the bacterial endosymbiont Carsonella. Science 314(5797), 267 (2006).

22. Glass JI, Lefkowitz EJ, Glass JS, Heiner CR, Chen EY, Cassell GH. The complete sequence of the mucosal pathogen Ureaplasma urealyticum. Nature 407, 757-762 (2000). 
23. Jaffe JD, Stange-Thomann N, Smith C et al. The complete genome and proteome of Mycoplasma mobile. Genome Res. 14, 1447-1461 (2004).

24. Grosche C, Rensing SA. Three rings for the evolution of plastid shape: a tale of land plant FtsZ. Protoplasma 254, 1879-1885 (2017).

25. Terbush AD, Maccready JS, Chen C, Ducat DC, Osteryoung KW. Conserved dynamics of chloroplast cytoskeletal FtsZ proteins across photosynthetic lineages. Plant Physiol. 176(1), 295-306 (2018).

26. Van Den Ent F, Amos LA, Löwe J. Bacterial ancestry of actin and tubulin. Curr. Opin. Microbiol. 4, 634-638 (2001).

27. Buske PJ, Levin PA. Extreme $\mathrm{C}$ terminus of bacterial cytoskeletal protein FtsZ plays fundamental role in assembly independent of modulatory proteins. J. Biol. Chem. 287, 10945-10957 (2012).

28. Rossmann MG, Moras D, Olsen KW. Chemical and biological evolution of nucleotide-binding protein. Nature 250(463), 194-199 (1974).

29. Corrales-Guerrero L, Camargo S, Valladares A et al. FtsZ of filamentous, heterocyst-forming cyanobacteria has a conserved $\mathrm{N}$-terminal peptide required for normal FtsZ polymerization and cell division. Front. Microbiol. 9, 2260 (2018).

30. Marbouty M, Saguez C, Cassier-Chauvat C, Chauvat F. Characterization of the FtsZ-interacting septal proteins SepF and Ftn6 in the spherical-celled cyanobacterium Synechocystis strain PCC 6803. J. Bacteriol. 191(19), 6178-6185 (2009).

31. Scheffers D-J, De Wit JG, Den Blaauwen T, Driessen AJM. GTP hydrolysis of cell division protein FtsZ: evidence that the active site is formed by the association of monomers. Biochemistry 41, 521-529 (2002).

32. Leung AKW, Lucile White E, Ross LJ, Reynolds RC, Devito JA, Borhani DW. Structure of Mycobacterium tuberculosis FtsZ reveals unexpected, G protein-like conformational switches. J. Mol. Biol. 342, 953-970 (2004).

33. Diaz JF, Kralicek A, Mingorance J, Palacios JM, Vicente M, Andreu JM. Activation of cell division protein FtsZ. Control of switch loop T3 conformation by the nucleotide gamma-phosphate. J. Biol. Chem. 276, 17307-17315 (2001).

34. Li Y, Hsin J, Zhao L et al. FtsZ protofilaments use a hinge-opening mechanism for constrictive force generation. Science 341, 392-395 (2013).

35. Matsui T, Han X, Yu J, Yao M, Tanaka I. Structural change in FtsZ induced by intermolecular interactions between bound GTP and the T7 loop. J. Biol. Chem. 289, 3501-3509 (2014).

36. Läppchen T, Pinas VA, Hartog AF et al. Probing FtsZ and tubulin with C8-substituted GTP analogs reveals differences in their nucleotide binding sites. Chem. Biol. 15(2), 189-199 (2008).

37. Wagstaff JM, Tsim M, Oliva MA et al. A polymerization-associated structural switch in FtsZ that enables treadmilling of model filaments. mBio 8(3), e00254-00217 (2017).

38. Shin JY, Vollmer W, Lagos R, Monasterio O. Glutamate 83 and arginine 85 of helix $\mathrm{H} 3$ bend are key residues for FtsZ polymerization, GTPase activity and cellular viability of Escherichia coli: lateral mutations affect FtsZ polymerization and E. coli viability. BMC Microbiol. 13, 26 (2013).

39. Guan $\mathrm{F}, \mathrm{Yu} \mathrm{J}, \mathrm{Yu} \mathrm{J}$ et al. Lateral interactions between protofilaments of the bacterial tubulin homolog FtsZ are essential for cell division. Elife 7, e35578 (2018).

40. Huang J, Cao C, Lutkenhaus J. Interaction between FtsZ and inhibitors of cell division. J. Bacteriol. 178(17), 5080-5085 (1996).

41. Cordell SC, Robinson EJH, Löwe J. Crystal structure of the SOS cell division inhibitor SulA and in complex with FtsZ. Proc. Natl Acad. Sci. USA 100(13), 7889-7894 (2003).

42. Blasios V, Bisson-Filho AW, Castellen P et al. Genetic and biochemical characterization of the MinC-FtsZ interaction in Bacillus subtilis. PLoS ONE 8(4), e60690 (2013).

43. Scheffers D-J. The effect of MinC on FtsZ polymerization is $\mathrm{pH}$ dependent and can be counteracted by ZapA. FEBS Lett. 582, 2601-2608 (2008).

44. Shen B, Lutkenhaus J. The conserved C-terminal tail of FtsZ is required for the septal localization and division inhibitory activity of $\operatorname{MinC}(\mathrm{C}) / \mathrm{MinD}$. Mol. Microbiol. 72(2), 410-424 (2009).

45. Shen B, Lutkenhaus J. Examination of the interaction between FtsZ and MinCN in E. coli suggests how MinC disrupts Z rings. Mol. Microbiol. 75(5), 1285-1298 (2010).

46. Buske PJ, Levin PA. A flexible C-terminal linker is required for proper FtsZ assembly in vitro and cytokinetic ring formation in vivo. Mol. Microbiol. 89, 249-263 (2013).

47. Gardner KA, Moore DA, Erickson HP. The C-terminal linker of Escherichia coli FtsZ functions as an intrinsically disordered peptide. Mol. Microbiol. 89(2), 264-275 (2013).

48. Huecas S, Ramirez-Aportela E, Vergonos A et al. Self-organization of FtsZ polymers in solution reveals spacer role of the disordered C-terminal tail. Biophys. J. 113(8), 1831-1844 (2017).

49. Levin PA, Kurtser IG, Grossman AD. Identification and characterization of a negative regulator of FtsZ ring formation in Bacillus subtilis. Proc. Natl Acad. Sci. USA 96, 9642-9647 (1999). 
50. Singh JK, Makde RD, Kumar V, Panda D. A membrane protein, EzrA, regulates assembly dynamics of FtsZ by interacting with the C-terminal tail of FtsZ. Biochemistry 46, 11013-11022 (2007).

51. Hu Z, Mukherjee A, Pichoff S, Lutkenhaus J. The MinC component of the division site selection system in Escherichia coli interacts with FtsZ to prevent polymerization. Proc. Natl Acad. Sci. USA 96, 14819-14824 (1999).

52. Dajkovic A, Lan G, Sun SX, Wirtz D, Lutkenhaus J. MinC spatially controls bacterial cytokinesis by antagonizing the scaffolding function of FtsZ. Curr. Biol. 18, 235-244 (2008).

53. Bernhardt TG, De Boer PA. SlmA, a nucleoid-associated, FtsZ binding protein required for blocking septal ring assembly over chromosomes in E. coli. Mol. Cell 18, 555-564 (2005).

54. Du S, Lutkenhaus J. SlmA antagonism of FtsZ assembly employs a two-pronged mechanism like MinCD. PLoS Genet. 10, e1004460 (2014).

55. Schumacher MA, Zeng W. Structures of the nucleoid occlusion protein SlmA bound to DNA and the C-terminal domain of the cytoskeletal protein FtsZ. Proc. Natl Acad. Sci. USA 113, 4988-4993 (2016).

56. Ma X, Margolin W. Genetic and functional analyses of the conserved C-terminal core domain of Escherichia coli FtsZ. J. Bacteriol. 181, 7531-7544 (1999).

57. Wang XD, Huang JA, Mukherjee A, Cao C, Lutkenhaus J. Analysis of the interaction of FtsZ with itself, GTP, and FtsA. J. Bacteriol. 179(17), 5551-5559 (1997).

58. Yan K, Pearce KH, Payne DJ. A conserved residue at the extreme C-terminus of FtsZ is critical for the FtsA-FtsZ interaction in Staphylococcus aureus. Biochem. Biophys. Res. Commun. 270(2), 387-392 (2000).

59. Pazos M, Natale P, Vicente M. A specific role for the ZipA protein in cell division: stabilization of the FtsZ protein. J. Biol. Chem. 288, 3219-3226 (2013).

60. Hale CA, De Boer PA. Direct binding of FtsZ to ZipA, an essential component of the septal ring structure that mediates cell division in E. coli. Cell 88, 175-185 (1997).

61. Hale CA, Rhee ZC, De Boer PA. ZipA-induced bundling of FtsZ polymers mediated by an interaction between C-terminal domains. J. Bacteriol. 182(18), 5153-5166 (2000).

62. Mosyak L, Zhang Y, Glasfeld E et al. The bacterial cell-division protein ZipA and its interaction with an FtsZ fragment revealed by X-ray crystallography. EMBO J. 19(13), 3179-3191 (2000).

63. Król E, Van Kessel SP, Van Bezouwen LS, Kumar N, Boekema EJ, Scheffers DJ. Bacillus subtilis SepF binds to the C-terminus of FtsZ. PLoS ONE 7, e43293 (2012).

64. Durand-Heredia J, Rivkin E, Fan G, Morales J, Janakiraman A. Identification of ZapD as a cell division factor that promotes the assembly of FtsZ in Escherichia coli. J. Bacteriol. 194, 3189-3198 (2012).

65. Durand-Heredia JM, Yu HH, De Carlo S, Lesser CF, Janakiraman A. Identification and characterization of ZapC, a stabilizer of the FtsZ ring in Escherichia coli. J. Bacteriol. 193, 1405-1413 (2011).

66. Addinall SG, Bi E, Lutkenhaus J. FtsZ ring formation in fts mutants. J. Bacteriol. 178(13), 3877-3884 (1996).

67. Monahan LG, Robinson A, Harry EJ. Lateral FtsZ association and the assembly of the cytokinetic Z ring in bacteria. Mol. Microbiol. 74, 1004-1017 (2009).

68. Huecas S, Llorca O, Boskovic J, Martin-Benito J, Valpuesta JM, Andreu JM. Energetics and geometry of FtsZ polymers: nucleated self-assembly of single protofilaments. Biophys. J. 94, 1796-1806 (2008).

69. Mukherjee A, Lutkenhaus J. Dynamic assembly of FtsZ regulated by GTP hydrolysis. EMBO J. 17(2), $462-469$ (1998).

70. Lu CL, Reedy M, Erickson HP. Straight and curved conformations of FtsZ are regulated by GTP hydrolysis. J. Bacteriol. 182, 164-170 (2000).

71. Ward JEJ, Lutkenhaus J. Overproduction of FtsZ induces minicell formation in E. coli. Cell 42, 941-949 (1985).

72. Anderson DE, Gueiros-Filho FJ, Erickson HP. Assembly dynamics of FtsZ rings in Bacillus subtilis and Escherichia coli and effects of FtsZ-regulating proteins. J. Bacteriol. 186, 5775-5781 (2004).

73. Bisson-Filho AW, Hsu Y-P, Squyres GR et al. Treadmilling by FtsZ filaments drives peptidoglycan synthesis and bacterial cell division. Science 355, 739-743 (2017).

-• Reports on the mechanisms that trigger divisome constriction and septal peptidoglycan synthesis during cell division in Bacillus subtilis.

74. Stricker J, Maddox P, Salmon ED, Erickson HP. Rapid assembly dynamics of the Escherichia coli FtsZ-ring demonstrated by fluorescence recovery after photobleaching. Proc. Natl Acad. Sci. USA 99, 3171-3175 (2002).

75. Yang X, Lyu Z, Miguel A, Mcquillen R, Huang KC, Xiao J. GTPase activity-coupled treadmilling of the bacterial tubulin FtsZ organizes septal cell wall synthesis. Science 355, 744-747 (2017).

76. Loose M, Mitchison TJ. The bacterial cell division proteins FtsA and FtsZ self-organize into dynamic cytoskeletal patterns. Nat. Cell Biol. 16, 38-46 (2014). 
77. Du S, Pichoff S, Kruse K, Lutkenhaus J. FtsZ filaments have the opposite kinetic polarity of microtubules. Proc. Natl Acad. Sci. USA 115, 10768-10773 (2018).

78. Monteiro JM, Pereira AR, Reichmann NT et al. Peptidoglycan synthesis drives an FtsZ-treadmilling-independent step of cytokinesis. Nature 554, 528-532 (2018).

- Reports on the mechanisms that trigger divisome constriction and septal peptidoglycan synthesis during cell division in Staphylococcus aureus.

79. Perez AJ, Cesbron Y, Shaw SL et al. Movement dynamics of divisome proteins and PBP2x: FtsW in cells of Streptococcus pneumoniae. Proc. Natl Acad. Sci. USA 116, 3211-3220 (2019).

80. Lan G, Wolgemuth CW, Sun SX. Z-ring force and cell shape during division in rod-like bacteria. Proc. Natl Acad. Sci. USA 104, 16110-16115 (2007).

81. Osawa M, Anderson DE, Erickson HP. Reconstitution of contractile FtsZ rings in liposomes. Science 320, 792-794 (2008).

82. Coltharp C, Buss J, Plumer TM, Xiao J. Defining the rate-limiting processes of bacterial cytokinesis. Proc. Natl Acad. Sci. USA 113(8), E1044-1053 (2016).

83. Nguyen LT, Oikonomou CM, Ding HJ et al. Simulations suggest a constrictive force is required for Gram-negative bacterial cell division. Nat. Commun. 10(1), 1259 (2019).

84. Osawa M, Erickson HP. Turgor pressure and possible constriction mechanisms in bacterial division. Front. Microbiol. 9, 111 (2018).

85. Migocki MD, Freeman MK, Wake RG, Harry EJ. The Min system is not required for precise placement of the midcell Z ring in Bacillus subtilis. EMBO Rep. 3, 1163-1167 (2002).

86. Yu XC, Margolin W. FtsZ ring clusters in min and partition mutants: role of both the Min system and the nucleoid in regulating FtsZ ring localization. Mol. Microbiol. 32, 315-326 (1999).

87. Mulder E, Woldringh CL. Actively replicating nucleoids influence positioning of division sites in Escherichia coli filaments forming cells lacking DNA. J. Bacteriol. 171, 4303-4314 (1989).

88. Woldringh CL, Mulder E, Valkenburg JaC, Wientjes FB, Zaritsky A, Nanninga N. Role of the nucleoid in the toporegulation of division. Res. Microbiol. 141, 39-49 (1990).

89. Wu LJ, Errington J. Coordination of cell division and chromosome segregation by a nucleoid occlusion protein in Bacillus subtilis. Cell 117, 915-925 (2004).

90. Adams DW, Wu LJ, Errington J. Nucleoid occlusion protein Noc recruits DNA to the bacterial cell membrane. EMBO J. 34(4), 491-501 (2015).

91. Wu LJ, Ishikawa S, Kawai Y, Oshima T, Ogasawara N, Errington J. Noc protein binds to specific DNA sequences to coordinate cell division with chromosome segregation. EMBO J. 28(13), 1940-1952 (2009).

92. Cho H, Mcmanus HR, Dove SL, Bernhardt TG. Nucleoid occlusion factor SlmA is a DNA-activated FtsZ polymerization antagonist. Proc. Natl Acad. Sci. USA 108(9), 3773-3778 (2011).

93. Cho H, Bernhardt TG. Identification of the SlmA active site responsible for blocking bacterial cytokinetic ring assembly over the chromosome. PLoS Genet. 9, e1003304 (2013).

94. Du S, Park KT, Lutkenhaus J. Oligomerization of FtsZ converts the FtsZ tail motif (conserved carboxy-terminal peptide) into a multivalent ligand with high avidity for partners ZipA and SlmA. Mol. Microbiol. 95(2), 173-188 (2015).

95. Tonthat NK, Milam SL, Chinnam N, Whitfill T, Margolin W, Schumacher MA. SlmA forms a higher-order structure on DNA that inhibits cytokinetic Z-ring formation over the nucleoid. Proc. Natl Acad. Sci. USA 110(26), 10586-10591 (2013).

96. Lenarcic R, Halbedel S, Shaw M et al. Localisation of DivIVA by targeting to negatively curved membranes. EMBO J. 28(15), 2272-2282 (2009).

97. Bramkamp M, Emmins R, Weston L, Donovan C, Daniel RA, Errington J. A novel component of the division-site selection system of Bacillus subtilis and a new mode of action for the division inhibitor MinCD. Mol. Microbiol. 70(6), 1556-1569 (2008).

98. Patrick JE, Kearns DB. MinJ (YvjD) is a topological determinant of cell division in Bacillus subtilis. Mol. Microbiol. 70, 1166-1179 (2008).

99. De Boer PA, Crossley RE, Rothfield LI. A division inhibitor and a topological specificity factor coded for by the minicell locus determine proper placement of the division septum in E. coli. Cell 56(4), 641-649 (1989).

100. Fu X, Shih Y-L, Zhang Y, Rothfield LI. The MinE ring required for proper placement of the division site is a mobile structure that changes its cellular location during the Escherichia coli division cycle. Proc. Natl Acad. Sci. USA 98(3), 980-985 (2001).

101. Hu Z, Saez C, Lutkenhaus J. Recruitment of MinC, an inhibitor of Z-Ring formation, to the membrane in Escherichia coli: role of MinD and MinE. J. Bacteriol. 185(1), 196-203 (2003).

102. Hu Z, Lutkenhaus J. Topological regulation of cell division in Escherichia coli involves rapid pole to pole oscillation of the division inhibitor MinC under the control of MinD and MinE. Mol. Microbiol. 34(1), 82-90 (1999).

103. Raskin DM, De Boer PA. MinDE-dependent pole-to-pole oscillation of division inhibitor MinC in Escherichia coli. J. Bacteriol. 181(20), 6419-6424 (1999). 
104. Raskin DM, De Boer PA. Rapid pole-to-pole oscillation of a protein required for directing division to the middle of Escherichia coli. Proc. Natl Acad. Sci. USA 96(9), 4971-4976 (1999).

105. Hale CA, Meinhardt H, De Boer PA. Dynamic localization cycle of the cell division regulator MinE in Escherichia coli. EMBO J. 20(7), 1563-1572 (2001).

106. Bailey MW, Bisicchia P, Warren BT, Sherratt DJ, Männik J. Evidence for divisome localization mechanisms independent of the Min system and SlmA in Escherichia coli. PLoS Genet. 10(8), e1004504 (2014).

107. Rodrigues CDA, Harry EJ. The Min system and nucleoid occlusion are not required for identifying the division site in Bacillus subtilis but ensure its efficient utilization. PLoS Genet. 8, e1002561 (2012).

108. Kiekebusch D, Michie KA, Essen LO, Löwe J, Thanbichler M. Localized dimerization and nucleoid binding drive gradient formation by the bacterial cell division inhibitor MipZ. Mol. Cell. 46(3), 245-259 (2012).

109. Thanbichler M, Shapiro L. MipZ, a spatial regulator coordinating chromosome segregation with cell division in Caulobacter. Cell 126(1), 147-162 (2006).

110. Treuner-Lange A, Aguiluz K, Van Der Does C et al. PomZ, a ParA-like protein, regulates Z-ring formation and cell division in Myxococcus xanthus. Mol. Microbiol. 87(2), 235-253 (2013).

111. Van Raaphorst R, Kjos M, Veening JW. Chromosome segregation drives division site selection in Streptococcus pneumoniae. Proc. Natl Acad. Sci. USA 114, E5959-E5968 (2017).

112. Fleurie A, Lesterlin C, Manuse S et al. MapZ marks the division sites and positions FtsZ rings in Streptococcus pneumoniae. Nature 516(7530), 259 (2014).

113. Holečková N, Doubravová L, Massidda O et al. LocZ is a new cell division protein involved in proper septum placement in Streptococcus pneumoniae. mBio 6, e01700-01714 (2014).

114. Willemse J, Borst JW, De Waal E, Bisseling T, Van Wezel GP. Positive control of cell division: FtsZ is recruited by SsgB during sporulation of Streptomyces. Genes Dev. 25(1), 89-99 (2011).

115. Pinho MG, Errington J. A divIVA null mutant of Staphylococcus aureus undergoes normal cell division. FEMS Microbiol. Lett. 240(2), 145-149 (2004).

116. Veiga H, Jorge AM, Pinho MG. Absence of nucleoid occlusion effector Noc impairs formation of orthogonal FtsZ rings during Staphylococcus aureus cell division. Mol. Microbiol. 80(5), 1366-1380 (2011).

117. Pang T, Wang X, Lim HC, Bernhardt TG, Rudner DZ. The nucleoid occlusion factor Noc controls DNA replication initiation in Staphylococcus aureus. PLoS Genet. 13, e1006908 (2017).

118. Hajduk IV, Rodrigues CDA, Harry EJ. Connecting the dots of the bacterial cell cycle: coordinating chromosome replication and segregation with cell division. Semin. Cell Dev. Biol. 53, 2-9 (2016).

119. Harry EJ, Rodwell J, Wake RG. Co-ordinating DNA replication with cell division in bacteria: a link between the early stages of a round of replication and mid-cell Z ring assembly. Mol. Microbiol. 33(1), 33-40 (1999).

120. Moriya S, Rashid RA, Rodrigues CDA, Harry EJ. Influence of the nucleoid and the early stages of DNA replication on positioning the division site in Bacillus subtilis. Mol. Microbiol. 76(3), 634-647 (2010).

121. Cambridge J, Blinkova A, Magnan D, Bates D, Walker JR. A replication-inhibited unsegregated nucleoid at mid-cell blocks Z-ring formation and cell division independently of SOS and the SImA nucleoid occlusion protein in Escherichia coli. J. Bacteriol. 196(1), 36-49 (2014).

122. Männik J, Bailey MW. Spatial coordination between chromosomes and cell division proteins in Escherichia coli. Front. Microbiol. 6, 306 (2015).

123. Monterroso B, Zorrilla S, Sobrinos-Sanguino M et al. The bacterial DNA binding protein MatP involved in linking the nucleoid terminal domain to the divisome at midcell interacts with lipid membranes. mBio 10(3), e00376-00319 (2019).

124. Du S, Lutkenhaus J. Assembly and activation of the Escherichia coli divisome. Mol. Microbiol. 105(2), 177-187 (2017).

125. Aarsman MEG, Piette A, Fraipont C, Vinkenvleugel TMF, Nguyen-Distèche M, Den Blaauwen T. Maturation of the Escherichia coli divisome occurs in two steps. Mol. Microbiol. 55(6), 1631-1645 (2005).

126. Gamba P, Veening JW, Saunders NJ, Hamoen LW, Daniel RA. Two-step assembly dynamics of the Bacillus subtilis divisome. J. Bacteriol. 191(13), 4186-4194 (2009).

127. Goley ED, Yeh YC, Hong SH et al. Assembly of the Caulobacter cell division machine. Mol. Microbiol. 80(6), 1680-1698 (2011).

128. Goley ED, Dye NA, Werner JN, Gitai Z, Shapiro L. Imaging-based identification of a critical regulator of FtsZ protofilament curvature in Caulobacter. Mol. Cell. 39(6), 975-987 (2010).

129. Osorio A, Camarena L, Cevallos MA, Poggio S. A new essential cell division protein in Caulobacter crescentus. J. Bacteriol. 199(8), e00811-00816 (2017).

130. Busiek KK, Margolin W. Bacterial actin and tubulin homologs in cell growth and division. Curr. Biol. 25(6), R243-R254 (2015). 
131. Van Den Ent F, Löwe J. Crystal structure of the cell division protein FtsA from Thermotoga maritima. EMBO J. 19(20), 5300-5307 (2000).

132. Bork P, Sander C, Valencia A. An ATPase domain common to prokaryotic cell cycle proteins, sugar kinases, actin, and hsp70 heat shock proteins. Proc. Natl Acad. Sci. USA 89(16), 7290-7294 (1992).

133. Pichoff S, Lutkenhaus J. Tethering the $\mathrm{Z}$ ring to the membrane through a conserved membrane targeting sequence in FtsA. Mol. Microbiol. 55(6), 1722-1734 (2005).

134. Haney SA, Glasfeld E, Hale C, Keeney D, He Z, De Boer P. Genetic analysis of the Escherichia coli FtsZ-ZipA interaction in the yeast two-hybrid system. Characterization of FtsZ residues essential for the interactions with ZipA and with FtsA. J. Biol. Chem. 276(15), 11980-11987 (2001).

135. Pichoff S, Lutkenhaus J. Identification of a region of FtsA required for interaction with FtsZ. Mol. Microbiol. 64(4), 1129-1138 (2007).

136. Szwedziak P, Wang Q, Freund SMV, Löwe J. FtsA forms actin-like protofilaments. EMBO J. 31(10), 2249-2260 (2012).

137. Lara B, Rico AI, Petruzzelli S et al. Cell division in cocci: localization and properties of the Streptococcus pneumoniae FtsA protein. Mol. Microbiol. 55(3), 699-711 (2005).

138. Krupka M, Cabre EJ, Jimenez M, Rivas G, Rico AI, Vicente M. Role of the FtsA C terminus as a switch for polymerization and membrane association. mBio. 5(6), e02221 (2014).

139. Krupka M, Rowlett VW, Morado D et al. Escherichia coli FtsA forms lipid-bound minirings that antagonize lateral interactions between FtsZ protofilaments. Nat. Commun. 8, 15957 (2017).

140. Krupka M, Margolin W. Unite to divide: oligomerization of tubulin and actin homologs regulates initiation of bacterial cell division. F1000Res. 7, 235 (2018).

141. Schoenemann KM, Krupka M, Rowlett VW, Distelhorst SL, Hu B, Margolin W. Gain-of-function variants of FtsA form diverse oligomeric structures on lipids and enhance FtsZ protofilament bundling. Mol. Microbiol. 109(5), 676-693 (2018).

142. Conti J, Viola MG, Camberg JL. FtsA reshapes membrane architecture and remodels the Z-ring in Escherichia coli. Mol. Microbiol. 107(4), 558-576 (2018).

143. Addinall SG, Lutkenhaus J. FtsA is localized to the septum in an FtsZ-dependent manner. J. Bacteriol. 178, 7167-7172 (1996).

144. Beall B, Lutkenhaus J. Impaired cell division and sporulation of a Bacillus subtilis strain with the ftsA gene deleted. J. Bacteriol. 174(7), 2398-2403 (1992).

145. Jensen SO, Thompson LS, Harry EJ. Cell division in Bacillus subtilis: FtsZ and FtsA association is Z-ring independent, and FtsA is required for efficient midcell Z-ring assembly. J. Bacteriol. 187(18), 6536-6544 (2005).

146. Mura A, Fadda D, Perez AJ et al. Roles of the essential protein FtsA in cell growth and division in Streptococcus pneumoniae.J. Bacteriol. 199, e00608-00616 (2017).

147. Haeusser DP, Rowlett VW, Margolin W. A mutation in Escherichia coli ftsZ bypasses the requirement for the essential division gene zipA and confers resistance to FtsZ assembly inhibitors by stabilizing protofilament bundling. Mol. Microbiol. 97, 988-1005 (2015).

148. Krupka M, Sobrinos-Sanguino M, Jiménez M, Rivas G, Margolin W. Escherichia coli ZipA organizes FtsZ polymers into dynamic ring-like protofilament structures. mBio 9, e01008-01018 (2018).

149. Geissler B, Elraheb D, Margolin W. A gain-of-function mutation in fts $A$ bypasses the requirement for the essential cell division gene $z i p A$ in Escherichia coli. Proc. Natl Acad. Sci. USA 100, 4197-4202 (2003).

150. Pichoff S, Shen B, Sullivan B, Lutkenhaus J. FtsA mutants impaired for self-interaction bypass ZipA suggesting a model in which FtsA's self-interaction competes with its ability to recruit downstream division proteins. Mol. Microbiol. 83, 151-167 (2012).

151. Vega DE, Margolin W. Direct interaction between the two Z ring membrane anchors FtsA and ZipA. J. Bacteriol. 5452, JB.00579-00518 (2018) (Epub ahead of print).

152. Camberg JL, Hoskins JR, Wickner S. ClpXP protease degrades the cytoskeletal protein, FtsZ, and modulates FtsZ polymer dynamics. Proc. Natl Acad. Sci. USA 106, 10614-10619 (2009).

153. Hamoen LW, Meile JC, De Jong W, Noirot P, Errington J. SepF, a novel FtsZ-interacting protein required for a late step in cell division. Mol. Microbiol. 59, 989-999 (2006).

154. Ishikawa S, Kawai Y, Hiramatsu K, Kuwano M, Ogasawara N. A new FtsZ-interacting protein, YlmF, complements the activity of FtsA during progression of cell division in Bacillus subtilis. Mol. Microbiol. 60, 1364-1380 (2006).

155. Gündoğdu ME, Kawai Y, Pavlendova N et al. Large ring polymers align FtsZ polymers for normal septum formation. EMBO J. 30, 617-626 (2011).

156. Duman R, Ishikawa S, Celik I et al. Structural and genetic analyses reveal the protein SepF as a new membrane anchor for the $\mathrm{Z}$ ring. Proc. Natl Acad. Sci. USA 110, E4601-4610 (2013).

157. Meier EL, Razavi S, Inoue T, Goley ED. A novel membrane anchor for FtsZ is linked to cell wall hydrolysis in Caulobacter crescentus. Mol. Microbiol. 101, 265-280 (2016). 
158. Gueiros-Filho FJ, Losick R. A widely conserved bacterial cell division protein that promotes assembly of the tubulin-like protein FtsZ. Genes Dev. 16(19), 2544-2556 (2002).

159. Pacheco-Gómez R, Cheng X, Hicks MR et al. Tetramerization of ZapA is required for FtsZ bundling. Biochem. J. 449, 795-802 (2013).

160. Small E, Marrington R, Rodger A et al. FtsZ polymer-bundling by the Escherichia coli ZapA orthologue, YgfE, involves a conformational change in bound GTP. J. Mol. Biol. 369(1), 210-221 (2007).

161. Dajkovic A, Pichoff S, Lutkenhaus J, Wirtz D. Cross-linking FtsZ polymers into coherent Z rings. Mol. Microbiol. 78, 651-668 (2010).

162. Mohammadi T, Ploeger GE, Verheul J et al. The GTPase activity of Escherichia coli FtsZ determines the magnitude of the FtsZ polymer bundling by ZapA in vitro. Biochemistry 48(46), 11056-11066 (2009).

163. Galli E, Gerdes K. FtsZ-ZapA-ZapB interactome of Escherichia coli. J. Bacteriol. 194(2), 292-302 (2012).

164. Buss JA, Peters NT, Xiao J, Bernhardt TG. ZapA and ZapB form an FtsZ-independent structure at midcell. Mol. Microbiol. 104, 652-663 (2017).

165. Schumacher M, Huang K-H, Zeng W, Janakiraman A. Structure of the Z ring associated protein, ZapD, bound to the C-terminal domain of the tubulin-like protein, FtsZ, suggests mechanism of $Z$ ring stabilization through Fts $Z$ crosslinking. J. Biol. Chem. 292(9), 3740-3750 (2017).

166. Woldemeskel SA, Mcquillen R, Hessel AM, Xiao J, Goley ED. A conserved coiled-coil protein pair focuses the cytokinetic Z-ring in Caulobacter crescentus. Mol. Microbiol. 105, 721-740 (2017).

167. Buss J, Coltharp C, Huang T et al. In vivo organization of the FtsZ-ring by ZapA and ZapB revealed by quantitative super-resolution microscopy. Mol. Microbiol. 89, 1099-1120 (2013).

168. Hale CA, Shiomi D, Liu B et al. Identification of Escherichia coli ZapC (YcbW) as a component of the division apparatus that binds and bundles FtsZ polymers. J. Bacteriol. 193, 1393-1404 (2011).

169. Du S, Pichoff S, Lutkenhaus J. FtsEX acts on FtsA to regulate divisome assembly and activity. Proc. Natl Acad. Sci. USA 113, E5052-E5061 (2016).

170. Meier EL, Daitch AK, Qing Y, Bhargava A, Jensen GJ, Goley ED. FtsEX-mediated regulation of inner membrane fusion and cell separation reveals 2 morphogenetic plasticity in Caulobacter crescentus. PLoS Genet. 13, e1006999 (2017).

171. Pichoff S, Du S, Lutkenhaus J. Roles of FtsEX in cell division. Res. Microbiol. 170(8), 374-380 (2019).

172. Domínguez-Cuevas P, Porcelli I, Daniel RA, Errington J. Differentiated roles for MreB-actin isologues and autolytic enzymes in Bacillus subtilis morphogenesis. Mol. Microbiol. 89, 1084-1098 (2013).

173. Meisner J, Llopis PM, Sham L-T, Garner EC, Bernhardt TG, Rudner DZ. FtsEX is required for CwlO peptidoglycan hydrolase activity during cell wall elongation in Bacillus subtilis. Mol. Microbiol. 89, 1069-1083 (2014).

174. Cleverley RM, Barrett JR, Baslé A et al. Structure and function of a spectrin-like regulator of bacterial cytokinesis. Nat. Commun. 5 , 5421 (2014).

175. Claessen D, Emmins R, Hamoen LW, Daniel RA, Errington J, Edwards DH. Control of the cell elongation-division cycle by shuttling of PBP1 protein in Bacillus subtilis. Mol. Microbiol. 68, 1029-1046 (2008).

176. Land AD, Luo Q, Levin PA. Functional domain analysis of the cell division inhibitor EzrA. PLoS ONE 9, e102616 (2014).

177. Haeusser DP, Schwartz RL, Smith AM, Oates ME, Levin PA. EzrA prevents aberrant cell division by modulating assembly of the cytoskeletal protein FtsZ. Mol. Microbiol. 52, 801-814 (2004).

178. Steele VR, Bottomley AL, Garcia-Lara J, Kasturiarachchi J, Foster SJ. Multiple essential roles for EzrA in cell division of Staphylococcus aureus. Mol. Microbiol. 80, 542-555 (2011).

179. Gamba P, Rietkötter E, Daniel RA, Hamoen LW. Tetracycline hypersensitivity of an ezrA mutant links GalE and TseB (YpmB) to cell division. Front. Microbiol. 6, 1-15 (2015).

180. Condon SGF, Mahbuba DA, Armstrong CR et al. The FtsLB subcomplex of the bacterial divisome is a tetramer with an uninterrupted FtsL helix linking the transmembrane and periplasmic regions. J. Biol. Chem. 293, 1623-1641 (2018).

181. Bisicchia P, Steel B, Debela MHM, Löwe J, Sherratt DJ. The N-terminal membrane-spanning domain of the Escherichia coli DNA translocase FtsK hexamerizes at midcell. mBio 4, 1-6 (2013).

182. Chen JC, Beckwith J. FtsQ, FtsL and Ftsl require FtsK, but not FtsN, for co-localization with FtsZ during Escherichia coli cell division. Mol. Microbiol. 42, 395-413 (2001).

183. Bottomley AL, Liew ATF, Kusuma KD et al. Coordination of chromosome segregation and cell division in Staphylococcus aureus. Front. Microbiol. 8, 1-13 (2017).

184. Daniel RA, Harry EJ, Errington J. Role of penicillin-binding protein PBP2B in assembly and functioning of the division machinery of Bacillus subtilis. Mol. Microbiol. 35, 299-311 (2000).

185. Liu B, Persons L, Lee L, De Boer PA. Roles for both FtsA and the FtsBLQ subcomplex in FtsN-stimulated cell constriction in Escherichia coli. Mol. Microbiol. 95, 945-970 (2015). 
186. Rowland SL, Wadsworth KD, Robson SA, Robichon C, Beckwith J, King GF. Evidence from artificial septal targeting and site-directed mutagenesis that residues in the extracytoplasmic $\beta$ domain of DivIB mediate its interaction with the divisomal transpeptidase PBP2B. J. Bacteriol. 192, 6116-6125 (2010).

187. Mohammadi T, Sijbrandi R, Lutters M et al. Specificity of the transport of lipid II by FtsW in Escherichia coli. J. Biol. Chem. 289, 14707-14718 (2014).

188. Meeske AJ, Eammon P, William P et al. SEDS proteins are a widespread family of bacterial cell wall polymerases. Nature 537, 634-638 (2016).

189. Taguchi A, Welsh MA, Marmont LS et al. FtsW is a peptidoglycan polymerase that is functional only in complex with its cognate penicillin-binding protein. Nat. Microbiol. 4, 587-594 (2019).

190. Mercer KLN, Weiss DS. The Escherichia coli cell division protein FtsW is required to recruit its cognate transpeptidase, FtsI (PBP3), to the division site. J. Bacteriol. 184, 904-912 (2002).

191. Fraipont C, Alexeeva S, Wolf B et al. The integral membrane FtsW protein and peptidoglycan synthase PBP3 form a subcomplex in Escherichia coli. Microbiology 157, 251-259 (2011).

192. Piette A, Fraipont C, Den Blaauwen T, Aarsman MEG, Pastoret S, Nguyen-Distèche M. Structural determinants required to target penicillin-binding protein 3 to the septum of Escherichia coli. J. Bacteriol. 186, 6110-6117 (2004).

193. Cleverley RM, Rutter ZJ, Rismondo J et al. The cell cylce regulator GpsB functions as cytosolic adaptor for multiple cell wall enzymes. Nat. Commun. 10, 1-17 (2019).

194. Tavares JR, De Souza RF, Meira GLS, Gueiros-Filho FJ. Cytological characterization of YpsB, a novel component of the Bacillus subtilis divisome. J. Bacteriol. 190, 7096-7107 (2008).

195. Pichoff S, Du S, Lutkenhaus J. Disruption of divisome assembly rescued by FtsN-FtsA interaction in Escherichia coli. Proc. Natl Acad. Sci. USA 115(29), E6855-e6862 (2018).

196. Gerding MA, Liu B, Bendezu FO, Hale CA, Bernhardt TG, De Boer PA. Self-enhanced accumulation of FtsN at division sites and roles for other proteins with a SPOR domain (DamX, DedD, and RlpA) in Escherichia coli cell constriction. J. Bacteriol. 191(24), 7383-7401 (2009).

197. Söderström B, Chan H, Shilling PJ, Skoglund U, Daley DO. Spatial separation of FtsZ and FtsN during cell division. Mol. Microbiol. 107, 387-401 (2018).

198. Artola M, Ruiz-Avila LB, Vergonós A et al. Effective GTP-replacing FtsZ inhibitors and antibacterial mechanism of action. ACS Chem. Biol. 10, 834-843 (2015).

199. Król E, De Sousa Borges A, Da Silva I et al. Antibacterial activity of alkyl gallates is a combination of direct targeting of FtsZ and permeabilization of bacterial membranes. Front. Microbiol. 6, 390 (2015).

200. Rai D, Singh JK, Roy N, Panda D. Curcumin inhibits FtsZ assembly: an attractive mechanism for its antibacterial activity. Biochem. J. 410, 147-155 (2008).

201. Mishra S, Narain U, Mishra R, Misra K. Design, development and synthesis of mixed bioconjugates of piperic acid-glycine, curcumin-glycine/alanine and curcumin-glycine-piperic acid and their antibacterial and antifungal properties. Bioorg. Med. Chem. 13(5), 1477-1486 (2005).

202. Kaur S, Modi NH, Panda D, Roy N. Probing the binding site of curcumin in Escherichia coli and Bacillus subtilis FtsZ - A structural insight to unveil antibacterial activity of curcumin. Eur. J. Med. Chem. 45(9), 4209-4214 (2010).

203. Morão LG, Polaquini CR, Kopacz M et al. A simplified curcumin targets the membrane of Bacillus subtilis. Microbiologyopen e683, 8(4), 1-12 (2019).

204. Cheng AL, Hsu CH, Lin JK et al. Phase I clinical trial of curcumin, a chemopreventive agent, in patients with high-risk or pre-malignant lesions. Anticancer Res. 21, 2895-2900 (2001).

205. Anand P, Kunnumakkara AB, Newman RA, Aggarwal BB. Bioavailability of curcumin: problems and promises. Mol. Pharm. 4, 807-818 (2007).

206. Jackson SJT, Murphy LL, Venema RC, Singletary KW, Young AJ. Curcumin binds tubulin, induces mitotic catastrophe, and impedes normal endothelial cell proliferation. Food Chem. Toxicol. 60, 431-438 (2013).

207. Plaza A, Keffer JL, Bifulco G, Lloyd JR, Bewley CA. Chrysophaentins A-H, antibacterial bisdiarylbutene macrocycles that inhibit the bacterial cell division protein FtsZ. J. Am. Chem. Soc. 132, 9069-9077 (2010).

208. Keffer JL, Huecas S, Hammill JT, Wipf P, Andreu JM, Bewley CA. Chrysophaentins are competitive inhibitors of FtsZ and inhibit Z-ring formation in live bacteria. Bioorg. Med. Chem. 21(18), 5673-5678 (2013).

209. Cerrutti P, Alzamora SM, Vidales SL. Vanillin as an antimicrobial for producing shelf-stable strawberry puree. J. Food Sci. 62, 608-610 (2006).

210. Sun J, Li M-H, Wang X-Y et al. Vanillin derivatives as the selective small molecule inhibitors of FtsZ. Med. Chem. Res. 23, 2985-2994 (2014). 
211. Possoz C, Newmark J, Sorto N, Sherratt DJ, Tolmasky ME. Sublethal concentrations of the aminoglycoside amikacin interfere with cell division without affecting chromosome dynamics. Antimicrob. Agents Chemother. 51, 252-256 (2007).

212. Schaffner-Barbero C, Martín-Fontecha M, Chacón P, Andreu JM. Targeting the assembly of bacterial cell division protein FtsZ with small molecules. ACS Chem. Biol. 7, 269-277 (2012).

213. Margalit DN, Romberg L, Mets RB et al. Targeting cell division: small-molecule inhibitors of FtsZ GTPase perturb cytokinetic ring assembly and induce bacterial lethality. Proc. Natl Acad. Sci. USA 101, 11821-11826 (2004).

214. Huang Q, Kirikae F, Kirikae T et al. Targeting FtsZ for antituberculosis drug discovery: noncytotoxic taxanes as novel antituberculosis agents. J. Med. Chem. 49, 463-466 (2006).

215. Singh D, Bhattacharya A, Rai A et al. SB-RA-2001 inhibits bacterial proliferation by targeting FtsZ assembly. Biochemistry 53 , 2979-2992 (2014).

216. Grycová L, Dostál J, Marek R. Quaternary protoberberine alkaloids. Phytochemistry 68, 150-175 (2007).

217. Boberek JM, Stach J, Good L. Genetic evidence for inhibition of bacterial division protein FtsZ by berberine. PLoS ONE 5, e13745 (2010).

218. Domadia PN, Bhunia A, Sivaraman J, Swarup S, Dasgupta D. Berberine targets assembly of Escherichia coli cell division protein FtsZ. Biochemistry 47, 3225-3234 (2008).

219. Park H-C, Gedi V, Cho J-H et al. Characterization and in vitro inhibition studies of Bacillus anthracis FtsZ: a potential antibacterial target. Appl. Biochem. Biotechnol. 172, 3263-3270 (2014).

220. Sun N, Chan F-Y, Lu Y-J et al. Rational design of berberine-based FtsZ inhibitors with broad-spectrum antibacterial activity. PLoS ONE 9, e97514 (2014).

221. Parhi A, Lu S, Kelley C, Kaul M, Pilch DS, Lavoie EJ. Antibacterial activity of substituted dibenzo[a,g]quinolizin-7-ium derivatives. Bioorg. Med. Chem. Lett. 22, 6962-6966 (2012).

222. Wang J, Yang T, Chen $\mathrm{H}$ et al. The synthesis and antistaphylococcal activity of 9, 13-disubstituted berberine derivatives. Eur. J. Med. Chem. 127, 424-433 (2017).

223. Sun N, Du R-L, Zheng Y-Y et al. Antibacterial activity of N-methylbenzofuro[3,2-b]quinoline and $\mathrm{N}$-methylbenzoindolo[3,2-b]-quinoline derivatives and study of their mode of action. Eur. J. Med. Chem. 135, 1-11 (2017).

224. Liu F, Venter H, Bi F et al. Synthesis and antibacterial activity of 5-methylphenanthridium derivatives as FtsZ inhibitors. Bioorg. Med. Chem. Lett. 27, 3399-3402 (2017).

225. Kelley C, Zhang Y, Parhi A, Kaul M, Pilch DS, Lavoie EJ. 3-phenyl substituted 6,7-dimethoxyisoquinoline derivatives as FtsZ-targeting antibacterial agents. Bioorg. Med. Chem. 20, 7012-7029 (2012).

226. Stermitz FR, Lorenz P, Tawara JN, Zenewicz LA, Lewis K. Synergy in a medicinal plant: antimicrobial action of berberine potentiated by 5-methoxyhydnocarpin, a multidrug pump inhibitor. Proc. Natl Acad. Sci. USA 97, 1433-1437 (2000).

227. Dziedzic A, Wojtyczka R, Kubina R. Inhibition of oral streptococci growth induced by the complementary action of berberine chloride and antibacterial compounds. Molecules 20, 13705-13724 (2015).

228. Zuo G-Y, Li Y, Han J, Wang G-C, Zhang Y-L, Bian Z-Q. Antibacterial and synergy of berberines with antibacterial agents against clinical multi-drug resistant isolates of methicillin-resistant Staphylococcus aureus (MRSA). Molecules 17, 10322-10330 (2012).

229. Li Z, Garner AL, Gloeckner C, Janda KD, Carlow CK. Targeting the Wolbachia cell division protein FtsZ as a new approach for antifilarial therapy. PLoS Negl. Trop. Dis. 5(11), e1411 (2011).

230. Acharya BR, Bhattacharya B, Chakrabarti G. The natural naphthoquinone plumbagin exhibits antiproliferative activity and disrupts the microtubule network through tubulin binding. Biochemistry 47, 7838-7845 (2008).

231. Aziz MH, Dreckschmidt NE, Verma AK. Plumbagin, a medicinal plant-derived naphthoquinone, is a novel inhibitor of the growth and invasion of hormone-refractory prostate cancer. Cancer Res. 68, 9024-9032 (2008).

232. Wang J, Galgoci A, Kodali S et al. Discovery of a small molecule that inhibits cell division by blocking FtsZ, a novel therapeutic target of antibiotics. J. Biol. Chem. 278, 44424-44428 (2003).

233. Noh TH, Sen L, Hong J, Lee J-H, Moon HR, Jung JH. Antibacterial activities of viriditoxin congeners and synthetic analogues against fish pathogens. Bioorg. Med. Chem. Lett. 27, 4970-4974 (2017).

234. Beuria TK, Santra MK, Panda D. Sanguinarine blocks cytokinesis in bacteria by inhibiting FtsZ assembly and bundling. Biochemistry 44, 16584-16593 (2005).

235. Croaker A, King GJ, Pyne JH, Anoopkumar-Dukie S, Simanek V, Liu L. Carcinogenic potential of sanguinarine, a phytochemical used in 'therapeutic' black salve and mouthwash. Mutat. Res. 774, 46-56 (2017).

236. Lopus M, Panda D. The benzophenanthridine alkaloid sanguinarine perturbs microtubule assembly dynamics through tubulin binding. FEBS J. 273, 2139-2150 (2006).

237. Panda P, Taviti AC, Satpati S, Kar MM, Dixit A, Beuria TK. Doxorubicin inhibits E. coli division by interacting at a novel site in FtsZ. Biochem. J. 471, 335-346 (2015). 
238. Minotti G, Menna P, Salvatorelli E, Cairo G, Gianni L. Anthracyclines: molecular advances and pharmacologic developments in antitumor activity and cardiotoxicity. Pharmacol. Rev. 56, 185-229 (2004).

239. Singh P, Jindal B, Surolia A, Panda D. A rhodanine derivative CCR-11 inhibits bacterial proliferation by inhibiting the assembly and GTPase activity of FtsZ. Biochemistry 51, 5434-5442 (2012).

240. Kumar K, Awasthi D, Lee S-Y et al. Novel trisubstituted benzimidazoles, targeting Mtb FtsZ, as a new class of antitubercular agents. J. Med. Chem. 54, 374-381 (2011).

241. Awasthi D, Kumar K, Knudson SE, Slayden RA, Ojima I. SAR studies on trisubstituted benzimidazoles as inhibitors of Mtb FtsZ for the development of novel antitubercular agents. J. Med. Chem. 56, 9756-9770 (2013).

242. Knudson SE, Awasthi D, Kumar K et al. Cell division inhibitors with efficacy equivalent to isoniazid in the acute murine Mycobacterium tuberculosis infection model. J. Antimicrob. Chemother. 70, 3070-3073 (2015).

243. Knudson SE, Kumar K, Awasthi D, Ojima I, Slayden RA. In vitro-in vivo activity relationship of substituted benzimidazole cell division inhibitors with activity against Mycobacterium tuberculosis. Tuberculosis 94, 271-276 (2014).

244. Ray S, Jindal B, Kunal K, Surolia A, Panda D. BT-benzo-29 inhibits bacterial cell proliferation by perturbing FtsZ assembly. FEBS J. 282, 4015-4033 (2015).

245. Domadia P, Swarup S, Bhunia A, Sivaraman J, Dasgupta D. Inhibition of bacterial cell division protein FtsZ by cinnamaldehyde. Biochem. Pharmacol. 74, 831-840 (2007).

246. Li X, Sheng J, Huang G et al. Design, synthesis and antibacterial activity of cinnamaldehyde derivatives as inhibitors of the bacterial cell division protein FtsZ. Eur. J. Med. Chem. 97, 32-41 (2015).

247. Chiang C-C, Cheng M-J, Peng C-F, Huang H-Y, Chen I-S. A novel dimeric coumarin analog and antimycobacterial constituents from Fatoua pilosa. Chem. Biodivers. 7, 1728-1736 (2010).

248. Duggirala S, Nankar RP, Rajendran S, Doble M. Phytochemicals as inhibitors of bacterial cell division protein FtsZ: coumarins are promising candidates. Appl. Biochem. Biotechnol. 174, 283-296 (2014).

249. Hemaiswarya S, Soudaminikkutty R, Narasumani ML, Doble M. Phenylpropanoids inhibit protofilament formation of Escherichia coli cell division protein FtsZ. J. Med. Microbiol. 60, 1317-1325 (2011).

250. Ohashi Y, Chijiiwa Y, Suzuki K et al. The lethal effect of a benzamide derivative, 3-methoxybenzamide, can be suppressed by mutations within a cell division gene, fts $Z$, in Bacillus subtilis. J. Bacteriol. 181, 1348-1351 (1999).

251. Czaplewski LG, Collins I, Boyd EA et al. Antibacterial alkoxybenzamide inhibitors of the essential bacterial cell division protein FtsZ. Bioorg. Med. Chem. Lett. 19, 524-527 (2009).

252. Haydon DJ, Stokes NR, Ure R et al. An inhibitor of FtsZ with potent and selective anti-staphylococcal activity. Science 321, 1673-1675 (2008).

-• Reports on the FtsZ inhibitor PC190723, a promising anti-staphylococcal drug candidate that exerts potent antimicrobial activity in murine models of methicillin-resistant Staphylococcus aureus (MRSA) infections.

253. Andreu JM, Schaffner-Barbero C, Huecas S et al. The antibacterial cell division inhibitor PC190723 is an FtsZ polymer-stabilizing agent that induces filament assembly and condensation. J. Biol. Chem. 285, 14239-14246 (2010).

254. Elsen NL, Lu J, Parthasarathy G et al. Mechanism of action of the cell-division inhibitor PC190723: modulation of FtsZ assembly cooperativity. J. Am. Chem. Soc. 134(30), 12342-12345 (2012).

255. Tan CM, Therien AG, Lu J et al. Restoring methicillin-resistant Staphylococcus aureus susceptibility to beta-lactam antibiotics. Sci. Transl. Med. 4(126), 126ra135 (2012).

-• Here, the authors show that PC190723 re-sensitizes MRSA to $\beta$-lactam antibiotics, highlighting the potential of FtsZ inhibitors as combination partners for the treatment of staphylococcal infections.

256. Adams DW, Wu LJ, Czaplewski LG, Errington J. Multiple effects of benzamide antibiotics on FtsZ function. Mol. Microbiol. 80(1), 68-84 (2011).

257. Artola M, Ruiz-Avila LB, Ramirez-Aportela E et al. The structural assembly switch of cell division protein FtsZ probed with fluorescent allosteric inhibitors. Chem. Sci. 8(2), 1525-1534 (2017).

258. Stokes NR, Baker N, Bennett JM et al. An improved small-molecule inhibitor of FtsZ with superior in vitro potency, drug-like properties, and in vivo efficacy. Antimicrob. Agents Chemother. 57, 317-325 (2013).

259. Kaul M, Mark L, Zhang Y, Parhi AK, Lavoie EJ, Pilch DS. Pharmacokinetics and in vivo antistaphylococcal efficacy of TXY541, a 1-methylpiperidine-4-carboxamide prodrug of PC190723. Biochem. Pharmacol. 86, 1699-1707 (2013).

260. Kaul M, Mark L, Zhang Y et al. TXA709, an FtsZ-targeting benzamide prodrug with improved pharmacokinetics and enhanced in vivo efficacy against methicillin-resistant Staphylococcus aureus. Antimicrob. Agents Chemother. 59, 4845-4855 (2015).

261. Hu Z, Zhang S, Zhou W, Ma X, Xiang G. Synthesis and antibacterial activity of 3-benzylamide derivatives as FtsZ inhibitors. Bioorg. Med. Chem. Lett. 27, 1854-1858 (2017). 
262. Kaul M, Mark L, Parhi AK, Lavoie EJ, Pilch DS. Combining the FtsZ-targeting prodrug TXA709 and the cephalosporin cefdinir confers synergy and reduces the frequency of resistance in methicillin-resistant Staphylococcus aureus. Antimicrob. Agents Chemother. 60(7), 4290-4296 (2016).

263. Lui HK, Gao W, Cheung KC et al. Boosting the efficacy of anti-MRSA beta-lactam antibiotics via an easily accessible, non-cytotoxic and orally bioavailable FtsZ inhibitor. Eur. J. Med. Chem. 163, 95-115 (2019).

264. Fujita J, Maeda Y, Mizohata E et al. Structural flexibility of an inhibitor overcomes drug resistance mutations in Staphylococcus aureus FtsZ. ACS Chem. Biol. 12(7), 1947-1955 (2017).

265. Sass P, Josten M, Famulla K et al. Antibiotic acyldepsipeptides activate ClpP peptidase to degrade the cell division protein FtsZ. Proc. Natl Acad. Sci. USA 108, 17474-17479 (2011).

-• Demonstrates that ADEP-antibiotics activate bacterial ClpP protease to degrade FtsZ, revealing an unprecedented strategy to target FtsZ and bacterial cell division.

266. Mayer C, Sass P, Brötz-Oesterhelt H. Consequences of dosing and timing on the antibacterial effects of ADEP antibiotics. Int. J. Med. Microbiol. 309(7), 151329 (2019).

267. Brötz-Oesterhelt H, Beyer D, Kroll H-P et al. Dysregulation of bacterial proteolytic machinery by a new class of antibiotics. Nat. Med. 11, 1082-1087 (2005).

268. Lee B-G, Park EY, Lee K-E et al. Structures of ClpP in complex with acyldepsipeptide antibiotics reveal its activation mechanism. Nat. Struct. Mol. Biol. 17, 471-479 (2010).

269. Li DH, Chung YS, Gloyd M et al. Acyldepsipeptide antibiotics induce the formation of a structured axial channel in ClpP: a model for the ClpX/ClpA-bound state of ClpP. Chem. Biol. 17(9), 959-969 (2010).

270. Pan S, Malik IT, Thomy D, Henrichfreise B, Sass P. The functional ClpXP protease of Chlamydia trachomatis requires distinct $c l p P$ genes from separate genetic loci. Sci. Rep. 9(1), 14129 (2019).

271. Kirstein J, Hoffmann A, Lilie $\mathrm{H}$ et al. The antibiotic ADEP reprogrammes ClpP, switching it from a regulated to an uncontrolled protease. EMBO Mol. Med. 1, 37-49 (2009).

272. Lowth BR, Kirstein-Miles J, Saiyed T et al. Substrate recognition and processing by a Walker B mutant of the human mitochondrial AAA+ protein ClpX. J. Struct. Biol. 179(2), 193-201 (2012).

273. Famulla K, Sass P, Malik I et al. Acyldepsipeptide antibiotics kill mycobacteria by preventing the physiological functions of the ClpP1P2 protease. Mol. Microbiol. 101, 194-209 (2016).

274. Gersch M, Famulla K, Dahmen M et al. AAA+ chaperones and acyldepsipeptides activate the ClpP protease via conformational control. Nat. Commun. 6, 6320 (2015).

275. Malik IT, Brötz-Oesterhelt H. Conformational control of the bacterial Clp protease by natural product antibiotics. Nat. Prod. Rep. 34(7), 815-831 (2017).

276. Silber N, Pan S, Schäkermann S et al. Cell division protein FtsZ is unfolded for N-terminal degradation by antibiotic-activated ClpP. mBio11(3), e01006-20 (2020).

277. Thomy D, Culp E, Adamek M et al. The ADEP biosynthetic gene cluster in Streptomyces hawaiiensis NRRL 15010 reveals an accessory clpP gene as a novel antibiotic resistance factor. Appl. Environ. Microbiol. 85(20), e01292-19 (2019)

278. Hinzen B, Raddatz S, Paulsen H et al. Medicinal chemistry optimization of acyldepsipeptides of the enopeptin class antibiotics. ChemMedChem 1, 689-693 (2006).

279. Carney DW, Schmitz KR, Truong JV, Sauer RT, Sello JK. Restriction of the conformational dynamics of the cyclic acyldepsipeptide antibiotics improves their antibacterial activity. J. Am. Chem. Soc. 136(5), 1922-1929 (2014).

280. Goodreid JD, Janetzko J, Santa Maria JP Jr et al. Development and characterization of potent cyclic acyldepsipeptide analogues with increased antimicrobial activity. J. Med. Chem. 59(2), 624-646 (2016).

281. Griffith EC, Zhao Y, Singh AP et al. Ureadepsipeptides as ClpP Activators. ACS Infect. Dis. 5(11), 1915-1925 (2019).

282. Brown Gandt A, Griffith EC, Lister IM et al. In vivo and in vitro effects of a ClpP-activating antibiotic against vancomycin-resistant enterococci. Antimicrob. Agents Chemother. 62(8), pii:e00424-18 (2018).

283. Conlon BP, Nakayasu ES, Fleck LE et al. Activated ClpP kills persisters and eradicates a chronic biofilm infection. Nature 503, 365-370 (2013).

- Reports on the synergistic activity of ADEP4 with rifampicin, an antibiotic combination that eradicates persisters, stationary and biofilm populations of MRSA in vitro and in a deep-seated murine infection.

284. Gil F, Paredes-Sabja D. Acyldepsipeptide antibiotics as a potential therapeutic agent against Clostridium difficile recurrent infections. Future Microbiol. 11, 1179-1189 (2016).

285. Ollinger J, O'malley T, Kesicki EA, Odingo J, Parish T. Validation of the essential ClpP protease in Mycobacterium tuberculosis as a novel drug target. J. Bacteriol. 194(3), 663-668 (2012).

286. Schiefer A, Vollmer J, Lammer C et al. The ClpP peptidase of Wolbachia endobacteria is a novel target for drug development against filarial infections. J. Antimicrob. Chemother. 68(8), 1790-1800 (2013). 
287. Arvanitis M, Li G, Li D-D et al. A conformationally constrained cyclic acyldepsipeptide is highly effective in mice infected with methicillin-susceptible and -resistant Staphylococcus aureus. PLoS ONE 11, e0153912 (2016).

288. Wong KS, Mabanglo MF, Seraphim TV et al. Acyldepsipeptide analogs dysregulate human mitochondrial ClpP protease activity and cause apoptotic cell death. Cell Chem. Biol. 25, 1017-1030.e1019 (2018).

289. Parti RP, Biswas D, Wang M, Liao M, Dillon JaR. A MinD mutant of enterohemorrhagic E. coli O157:H7 has reduced adherence to human epithelial cells. Microb. Pathog. 51, 378-383 (2011).

290. Raju RM, Unnikrishnan M, Rubin DH et al. Mycobacterium tuberculosis ClpP1 and ClpP2 function together in protein degradation and are required for viability in vitro and during infection. PLoS. Pathog. 8(2), e1002511 (2012). 
